\title{
¿La segunda parte del Catálogo Real de Castilla de Gonzalo Fernández de Oviedo en un manuscrito de la British Library? ${ }^{1}$
}

\section{The Second Part of Gonzalo Fernández de Oviedo's Catálogo Real de Castilla in a British Library Manuscript?}

\author{
José Manuel NieTo SoRIA \\ Universidad Complutense. Madrid \\ jmniesor@ucm.es
}

\section{RESUMEN}

Estudio de un manuscrito inédito encontrado en la British Library en el que se aborda desde el reinado de Enrique IV al de Carlos V, entre los años 1454 y 1536. Como resultado de este estudio se propone plantear la hipótesis de que el texto encontrado pueda ser la segunda parte del Catálogo Real de Castilla, obra de Gonzalo Fernández de Oviedo (1478-1557).

Palabras clave: Castilla, Siglo XV, Siglo XVI, Gonzalo Fernández de Oviedo, Catálogo Real de Castilla.

\begin{abstract}
A study of an unpublished manuscript found in the British Library which concerns the reign of Enrique IV of Castile to the reign of Charles V, between the year 1454 and 1536. As a result, a hypothesis is formulated in which the manuscript may be considered the second part of the Catálogo real de Castilla by Gonzalo Fernández de Oviedo (1478-1557).
\end{abstract}

Key words: Castile, 15th Century, 16th Century, Gonzalo Fernández de Oviedo, Catálogo Real de Castilla.

Sumario: 1. Origen y descripción general del manuscrito. 2. Indicios biográficos sobre la autoría de Gonzalo Fernández de Oviedo. 3. La obra de Gonzalo Fernández de Oviedo en sus conexiones con el manuscrito. 4. El proceso de redacción. 5. Temas y perspectivas. 6. Algunos apuntes sobre el estilo narrativo. 7. Conclusiones provisionales.

\footnotetext{
${ }^{1}$ Este trabajo forma parte del proyecto de investigación de la Secretaría de Investigación, Desarrollo e Innovación $n^{\circ}$ HAR2010-16762. Su realización ha sido también posible gracias a la acogida de que fui objeto como Research Fellow durante los meses de mayo y junio de 2012 y al seminario celebrado el 6 de diciembre de 2013 en el Medieval Hispanic Research Seminar (Queen Mary, London University). 
Dentro de la extensa obra historiográfica de Gonzalo Fernández Oviedo, tiene lugar propio su titulado Catálogo Real de Castilla y de todos los reyes de las Españas. Conservada a través de un único manuscrito perteneciente a los fondos de la Biblioteca del Real Monasterio de San Lorenzo de El Escorial², fue objeto en 1992 de la tesis doctoral de Ana Romano de Thuesen ${ }^{3}$. Calificada por José Amador de los Ríos como "el tratado más completo de la historia de España y de sus relaciones con los demás estados de Europa, de cuantos hacia fines del primer tercio del siglo XVI se escribieron"4. Dedicada, a establecer, como su título indica, un catálogo de los reyes españoles que remonta en su origen como el primero de ellos al rey Túbal, se interrumpe abruptamente con la finalización del reinado de Juan II de Castilla. Sin embargo, el propio Fernández de Oviedo anunciaba cómo este reinado de Juan II no suponía el final de su obra, sino el de lo que él mismo consideraba tan sólo como primera parte de un proyecto historiográfico que había de alcanzar hasta el momento mismo de su redacción, lo que suponía incluir lo que iba a partir de 1454 en adelante:

Con lo ques dicho se dará la final conclusión a esta primera parte o libro deste apostólico e del Real Catálogo, porque en el segundo volumen se tratará desdel rey don Enrrique, quarto rey de Castilla, e desdesdel[sic] rey don Johan de Aragón hasta el rey don Juan de Navarra, que perdió aquel reyno, hasta el Rey Cathólico don Fernando que ganó a Granada e a Nápoles. E después en su lugar se porná la relaçión sumaria de lo que tocare a la Çesárea Magestad del Emperador Rey, nuestro señor don Carlos, quinto de tal nombre, con el qual se acabarán de resumir todas las líneas de los rreyes de Castilla e de Aragón e Nápoles e de Navarra, e los duques de Borgoña e de los condes de Flandes, e de los condes de Holanda e de los emperadores, aviendo tanbién primero memorado el árbol de la rreal consanguinidad de los rreyes de Portugal, desde donde en esta parte çesaré hasta concluyr en el serenísimo rrey don Johan, que al presente reyna en Portugal"s.

En otro lugar de la misma obra anunciaba expresamente la redacción de una segunda parte:

La presente es desde el primero Rey de España hasta en fin de la vida del Serenísimo rey don Johan, segundo de tal nombre en Castilla, bisabuelo de Vuestra Magestad Carlos, con los otros reyes de Nauarra y Aragón e Portugal. E la segunda parte ha de ser desde allí hasta el tiempo presente" $\%$.

Bajo estas premisas, el hallazgo de un manuscrito en la British Library que recorre el periodo que va de 1454 a 1536, en el que nada se indica sobre la autoría, y bajo un formato narrativo que en todo se asemeja al empleado en la primera parte del Catálogo Real, junto con otras circunstancias que aquí serán objeto preferente de atención, me lleva a plantear ahora la hipótesis de que con este manuscrito nos podríamos encontrar ante esa segunda parte del Catálogo Real, obra de Gonzalo Fernández de

${ }^{2}$ Biblioteca del Real Monasterio de San Lorenzo de El Escorial, Ms. H.j.7.

${ }^{3}$ Romano de Thuesen, Ana:Transcripción y Edición del Catálogo Real de Castilla, autógrafo inédito de Gonzalo Fernández de Oviedo y Valdés Santa Bárbara (California), 1992.

${ }^{4}$ Amador de los Rios, José (ed.):Historia General y Natural de las Indias, Islas y Tierra firme del mar Océano, 4v., Madrid, 1851-1855), I, p. XCI.

${ }^{5}$ Biblioteca del Real Monasterio de San Lorenzo de El Escorial, H.I.7, fol. 398v.

${ }^{6}$ Ibid., fol. $1 \mathrm{r}$.. 
Oviedo, hasta ahora desconocida en su textualidad para la historia de la historiografía española.

\section{ORIGEN Y DESCRIPCIÓN GENERAL DEL MANUSCRITO}

Mientras que en el catálogo automatizado de la British Library el manuscrito ${ }^{7}$ es aludido como Crónica del rey Enrique $I V$, la única descripción del mismo se debe a Pascual Gayangos que lo presenta del siguiente modo 8 :

"Miscelánea Histórica" containing the following papers: Short chronicles of the reigns of Henry IV, Ferdinand and Isabella, Philip I and Joanna, treating at great length of that of Charles V to the end of 1536".

A la vista del manuscrito, se comprueba que ni se trata tan sólo de una crónica del reinado de Enrique IV, ni, como se anuncia en el catálogo de Gayangos, de un conjunto de crónicas breves, sino de una narración continuada de apariencia cronística que abarca el periodo 1454-1536, a la que se añaden al término de la misma varios documentos, de los cuales el más antiguo es de 1504 y el más moderno de 1542.

El manuscrito llega originalmente al por entonces British Museum de Londres como consecuencia de una compra realizada por esta institución a Thomas RoddBookseller, efectuada el 26 de julio de 1845. Este librero era uno de los proveedores habituales de esta institución, habiendo sucedido en el negocio a su padre, Thomas Rodd "The Elder"(1763-1822). De esta saga de libreros conviene destacar que contaron con una delegación en Alicante y que, sobre todo Thomas Rodd "The Elder", tuvo especial inclinación hacia la literatura española, lo que le llevó incluso a publicar alguna obra referente a temas españoles, en especial, relacionada con la época histórica de la guerra de Granada. En la Biblioteca Nacional de Madrid se encuentra parte del catálogo de venta de sus libros correspondiente a $1843^{9}$.

El manuscrito fue incorporado a los fondos del British Museum en 1879 y catalogado, tal como se ha descrito antes, por Pascual Gayangos en fechas inmediatas, aunque con una descripción que, como ya se ha visto, nada aportaba para su identificación y que más bien podría dificultarla.

El volumen en el que se encuentra incluye sólo esta obra, componiéndose de 136 folios escritos en letra que parece proceder de distintas manos de mediados del siglo XVI, presentando una distribución, en la que se diferencia claramente entre lo que es relato cronístico (hasta el folio 118) y el resto, hasta el 136, lo que es documentación complementaria. La parte narrativa se distribuye del siguiente modo:

${ }^{7}$ British Library, Additional, Ms. 15.568. En adelante será citado como BL-MS.

${ }^{8}$ Pascual Gayangos:Catalogue of the Manuscripts in Spanish Language in the British Museum, Londres, 1881, III, p. 313.

${ }^{9}$ Biblioteca Nacional de España, sign. U/3092, Catalogue of books, part I y Biblioteca Nacional de España, sign. U/3093 Catalogue of books, part III. 
Fols 1r-8v: 1454-1474.

Fols. 8v-20v: 1474-1504.

Fols. 21r-39r: 1504-1516.

Fols. 39r-118v: 1516-1536.

El comienzo de cada reinado va anunciado con un círculo dentro del cual va escrito el nombre del nuevo monarca, tal como también se observa en las Minutas del Epílogo Real, Imperial y Pontificio de Gonzalo Fernández de Oviedo.

El relato alcanza hasta mediados de diciembre de 1536, teniendo un carácter de crónica continua de los distintos reinados. Predomina, en general, un fuerte tono apologético hacia todos los monarcas. Dentro de este tono apologético que caracteriza el modo de tratar a los distintos monarcas cabe observar cómo hay un esfuerzo de dignificación de la memoria de Enrique $\mathrm{IV}^{10}$, una reivindicación muy acusada de exaltación de la figura de Isabel la Católica, a la que dota de un perfil de mujer y gobernante excepcional ${ }^{11}$ que contribuye a ensombrecer comparativamente, en cierto modo, a la figura de Fernando el Católico, lo que no impideque se presente también a éste bajo tintes manifiestamente elogiosos, a la vez que Felipe y Juana quedan en un plano muy secundario, rematándose con un enfoque que se da a los hechos de Carlos V que bien podría calificarse como de epopeya triunfal del emperador, del que se ofrece una imagen de héroe perfecto, mientras que se evidencia una actitud del autor de sincera admiración y profundo agradecimiento hacia la emperatriz Isabel de Portugal, de la que se destaca su papel de efectiva regente del reino en ausencia de su marido ${ }^{12}$, el emperador Carlos, con especial referencia en este sentido para el año 1532, momento para el que conocemos la proximidad de Fernández de Oviedo a dicha reina.

Desde el folio 119 hasta el final del manuscrito, en el folio 136, se reúnen copias de varios documentos. Son los siguientes:

El primero ${ }^{13}$ se refiere a la publicación por el Consejo Real el mismo día de la muerte de Isabel la Católica, de una pragmática dada por la reina referente a los abusos que grandes y caballeros venían cometiendo en la recaudación de la alcabala. El documento adquiere un valor singular por la noticia que da de la muerte de la reina con la que termina:

${ }^{10}$ Estaría en la línea de lo señalado en: CARRASco Manchado, Ana Isabel: "La memoria del conflicto en la formación de la conciencia política: la visión de Gonzalo Fernández de Oviedo sobre los reinados de Enrique IV y Reyes Católicos", Memoria e Historia: utilización política en la Corona de Castilla al final de la Edad Media, coord. por Jon Andoni Fernández de Larrea y Rojas, José Ramón Díaz de Durana Ortiz de Urbina, Vitoria, 2010, pp. 221-248.

11 'Y (a)cabó de sus dias, la exçelente reyna doña Ysabel, honra delas Españas, espejo de las mugeres, en la villa de Medina del Campo, a veynte y seis días del mes de noviembre, año del señor de mill e quinientos e quatro años, entre las honze y doze del día, más çerca delas doze horas. Con la qual muerte, todo el gozo que España tenía, peresçió (...) Desta reyna, considerada la fee, vida y religión fin, no sería temeridad afirmar que está en el çielo, o a lo menos que, purgadas algunas culpas de sus pecados, pues, como dize el apóstol, no ay justo ni quien pueda dezir que esté sin pecado, en brebe será colocada en la çelestial gloria con los santos, y que dexó reyno temporal para alcançarle en la gloria”.BL-MS. fol. 20v.

${ }^{12}$ Véase al respecto: Alvar EzQuerra, Alfredo: La emperatriz. Isabel y Carlos V, amor y gobierno en la corte española del Renacimiento, Madrid, 2012.

${ }^{13}$ BL-MS., fols., 119r-121r. 
Esta carta se leyó con el presidente y los del consejo por el secretario Juan López, a XXVI días del dicho mes de nouiembre de mil e quinientos e quatro años. Testigos que la oyeron leer e vieron publicar en el consejo el alcalde Gonzalo Ferrández Gallego e el licenciado Polanco, alcalde de la corte y el licenciado Francisdo de Bargas, teniente de contador mayor de sus altezas. Y fue a la mañana a las diez. La reyna doña Ysabel spiró cerca de las doze de mediodía"14.

El segundo y tercer documentos reiteran lo referido en la pragmática a la que se acaba de aludir, siendo uno dado por Carlos en Gante, a tres de abril de $1531^{15}$, e incluyendo el otro la publicación por la reina Isabel de Portugal en Medina del Campo, a 16 de noviembre del mismo año, de un documento de Carlos relativo a la misma cuestión $^{16}$.

El cuarto es la "carta que escribieron los moros de Argel a los moros de Valençia de la pasada del emperador nuestro señor, año de 1541"17.

El quinto es el "traslado de las çédulas del llamamiento que el emperador hizo a los grandes del reyno desde las cortes de Monçón, año 1542"18.

El sexto es la carta que escribe el emperador al duque de Alburquerque para hacerle saber de las victorias militares en Túnez y de la toma de La Goleta, llevando fecha de 19 de agosto de $1535^{19}$.

El séptimo recoge la relación de los acuerdos que integraban la capitulación pactada con el rey de Túnez en $1535^{20}$.

Por último, el octavo incluye "las nuevas que scriben Andrea Bellute de Trapana, que es en Siçilia, a tres de setiembre de 1535 años"21.

Por lo que se refiere a sus principales rasgos codicológicos, cabe señalar los siguientes:

Encuadernación en cartoné del XVIII o XIX.

Dimensiones de encuaderación: $305 \times 220$.

Dimensiones de folio: 296x205.

3 folios de guarda oprotección iniciales:

Folio $1^{\circ}$ en blanco.

Folio 2r: En letra del XIX: Purhased of Thomas Rodd 26 july 1845.

Folio 2v: Blanco.

Folio 3r: en la esquina superior izquierda anotación del siglo XVIII: $n^{\circ} 22$.

Folio 3v: a lápiz letra del XX :Enrique $I V$, Fernando y Isabel, Felipe y Juana, Carlos V Emperador.

Dos folios de guarda finales el penúltimo, a lápiz: “136 fols. Ex. In. Sep. 1879”.

Lomo con nervios y tejuelo, con letras doradas con el siguiente orden vertical: Crónica

\footnotetext{
${ }^{14}$ Ibid., fol. 121 r.

${ }^{15}$ Ibid., fol. $121 \mathrm{v}$.

${ }^{16} \mathrm{Ibid}$., fols. $122 \mathrm{r}-124 \mathrm{v}$.

${ }^{17}$ Ibid., fols. $125 \mathrm{r}-128 \mathrm{v}$.

${ }^{18} \mathrm{Ibid}$., fols. 129r-

${ }^{19}$ Ibid., fols. 131r-132r.

${ }^{20}$ Ibid., fols. 133r-134r.

${ }^{21}$ Ibid., fols. 135rv.
} 


Del Rey
Enrique
IV
M.S.
MUS.
BRIT.
JURE
EMPT.
15568
PLUT
CXCII.H

Lo correspondiente a Enrique IV se muestra muy próximo a planteamientos presentes en la crónica de Diego Enríquez del Castillo, cuya defensa de este monarca, sobre todo en la primera parte del reinado, previa a 1465 , se ve superada en el BLMS por la inclinación que se observa en este a resaltar cualidades personales de este rey. Apenas desliza muy ligeras críticas hacia las acciones del monarca en lo que se evidencia como situación de desgobierno en la segunda parte del reinado. Acepta sin reservas la condición de la Beltraneja como hija de Beltrán de la Cueva. Conviene advertir en este punto que Amador de los Ríos apuntó la hipótesis de que Gonzalo Fernández de Oviedo habría sido pariente de un secretario de Enrique IV de nombre Juan de Oviedo ${ }^{22}$, habiéndose constatado la presencia de distintos miembros de esta familia al servicio de este monarca ${ }^{23}$.Hay que señalar que, a pesar de la brevedad con que se aborda este reinado, se aportan algunos datos inéditos no contenidos en la cronística enriqueña anterior y que hacen pensar que, en tanto que si el autor no vivió durante ese reinado, sí pudo tener acceso a documentación de primera mano que le permitió conocer datos no historiados con anterioridad. A la vez, también hay que destacar cómo con relación a algunos acontecimientos relevantes, por ejemplo, la intervención de Enrique IV en Cataluña, el autor expresa motivaciones inéditas no consideradas en la cronística precedente sobre el comportamiento regio en este asunto ${ }^{24}$.

Lo correspondiente al periodo 1474-1516 coincide textualmente con una buena parte de los contenidos de lo que hasta ahora se ha conocido como la Continuación de la crónica de los Reyes Católicos de Pulgar por un anónimo ${ }^{25}$. Sin embargo, con relación a esta coincidencia textual hay que advertir que hay partes relevantes que no están en uno o en otro texto y que la parte final correspondiente a los últimos años de este intervalo es significativamente más extensa en el BL-MS que en la mencionada crónica. Del mismo modo, mientras que la Continuación empieza con las campañas de la Guerra de Granada, el BL-MS empieza con la proclamación de Isabel, co-

${ }^{22}$ Pérez de Tudela y Bueso, Juan: “Fernández de Oviedo y sus ‘Batallas y Quinquagenas', en Batallas y Quinquagenas, Madrid, I, 1983, p. XIII.

${ }^{23}$ Porras Arboledas, Pedro Andrés: Francisco Ramírez de Madrid (144?-1501). Primer madrileño al servicio de los Reyes Católicos, Madrid, 1996, pp. 31-40.

${ }^{24} \mathrm{BL}-\mathrm{MS}$, fol. $4 \mathrm{r}$.

${ }^{25}$ Crónicas de los reyes de Castilla, III, Biblioteca de Autores Españoles, vol. LXX, Madrid, 1953, pp. 514-531.. 
nectándola con la muerte de Enrique IV, produciéndose una clara continuidad entre Enrique IV e Isabel, lo que no sucede en la Continuación, que se muestra como incompleta por la parte de su comienzo.

Cotejado el manuscrito que se utilizó para la edición de la Continuación de la crónica de los Reyes Católicos de Pulgar por un anónimo ${ }^{26}$, se comprueba que se trata de una copia realizada en 1607 en la que se incluye la crónica de los Reyes Católicos de Pulgar, seguida, a partir del folio 356, de la Continuación, lo que haría compatible la existencia de ese texto con su procedencia como copia parcial de un texto o de varios textos cronísticos preexistentes de carácter más amplio, como el que se recoge en BL-MS. De esta continuación existe otro manuscrito procedente de la Real Academia de la Historia ${ }^{27}$, aunque, a la vista del mismo, no parece que fuera utilizado para la edición referida. Todo ello me llevaría a pensar que el texto aquí considerado tendría alguna circulación en la segunda mitad del siglo XVI, lo que permitiría servir de base para otras versiones cronísticas más tardías, en este caso específicamente referidas al reinado de los Reyes Católicos.

La parte correspondiente a la época de Carlos V nada tiene que ver con los textos cronísticos conocidos para el periodo, denotando el BL-MS un extenso manejo de correspondencia oficial, con especial presencia de procedente de la correspondencia de la emperatriz Isabel de Portugal y del Duque de Calabria ${ }^{28}$, a cuyo servicio estuvo Gonzalo Fernández de Oviedo, y con el que mantuvo continuada relación, más allá de los años en que trabajó para él ${ }^{29}$.

\section{INDICIOS BIOGRÁFICOS SOBRE LA AUTORÍA DE GONZALO FERNÁNDEZ DE OVIEDO}

Hay diversas circunstancias biográficas de la vida de Gonzalo Fernández de Oviedo que creo que bien pueden valorarse como indicios que juegan significativamente a favor de la autoría del escritor madrileño.

Teniendo en cuenta la extensa presencia de los acontecimientos políticos y, sobre todo, militares y ceremoniales que tienen lugar en la península italiana a lo largo del relato, resulta evidente cómo el autor posee un buen conocimiento de la geografía y de la política italiana, en especial, de lugares como Bolonia, Roma, Nápoles, Milán o Sicilia, siendo todos ellos directamente conocidos por el autor, por haber vivido en ellos $^{30}$. En efecto, su estancia en Italia, donde estuvo entre 1478 y 1502, le permitió

${ }^{26}$ Su texto procede de la Biblioteca Nacional de España, Ms. 8.215.

27 Biblioteca de la Real Academia de la Historia, Salazar y Castro, Ms. C-89.

${ }^{28}$ PARdo Molero, Juan Francisco: "El tercer Fernando: el duque de Calabria y la sucesión de los reinos hispánicos (1512-1522)", Fernando I, 1503-1564: socialización, vida privada y actividad pública de un Emperador del Renacimiento, coord. por F. Edelmayer y A. Alvar Ezquerra, Madrid, 2004, pp. 229-252 y López-Ríos Moreno, Santiago: "La educación de Fernando de Aragón, Duque de Calabria, durante su infancia y juventud (1488-1502)", La literatura en la época de los Reyes Católicos, coord. por N. Salvador Miguel y C. Moya García, Madrid, 2008, pp. 127-144.

${ }^{29}$ Ballesteros, Manuel: Gonzalo Fernández de Oviedo, Madrid, 1981, pp. 71-72.

30 "Si en tiempo no había sido larga la aventura italiana de Oviedo, se demostraría, en cambio, profunda en su huella", dejando un "parcial italianidad" en su persona. PéreZ de Tudela y Bueso, p. XVI. 
a Fernández de Oviedo adquirir amplia experiencia del mundo italiano, suponiendo un periodo de extraordinaria importancia para su enriquecimiento intelectual ${ }^{31}$. Descripciones que se ofrecen de distintos acontecimientos a lo largo del texto se hacen difícilmente comprensibles si no se tiene un conocimiento directo de los lugares aludidos ${ }^{32}$. Además, esta estancia italiana fue fructífera a largo plazo, puesto que sabemos que mantuvo correspondencia prolongada mucho tiempo después de su marcha de Italia con algunos de los protagonistas más destacados de la actividad militar y política de Fernando el Católico y de Carlos V en este escenario, siendo este, en especial, el caso del duque de Calabria, cuyas cartas pudieran haber dado sustento a algunas descripciones plasmadas en el manuscrito.

Se comprueba, por otra parte, un encaje bastante coherente entre el distinto nivel de riqueza informativa del texto, en cuanto a su mayor pobreza de contenidos, en coincidencia con lo que fueron los periodos de ausencia de Gonzalo Fernández de Oviedo con motivo de su marcha a América. Así se nota mucho esta, si se quiere llamar así, crisis informativa para los últimos años del reinado de Fernando el Católico, en coincidencia con su marcha a América entre 1514 y 1516. Para este periodo, apenas alude a algunos de los movimientos del monarca de manera muy parca a partir del momento en que da noticia de su enfermedad en 1513, saltando ya a la referencia que se hace en el manuscrito a cómo el monarca parte de Plasencia para dirigirse a Sevilla, falleciendo en Madrigalejo durante el trayecto ${ }^{33}$, dándose precisamente la circunstancia de que Fernández de Oviedo se había presentado ante el rey en Plasen$\mathrm{cia}^{34}$.

Por el contrario, los momentos en que se sabe que Gonzalo Fernández de Oviedo se halla en la corte son coincidentes con la presencia de informaciones especialmente abundantes y detalladas sobre movimientos, actividades y situaciones de la propia corte, tal como se observa, por ejemplo, para los años 1523-1526, con amplias noticias de la vida de la corte, así como de 1532. En Madrid se encuentra este autor en coincidencia con la llegada como prisionero de Francisco I de Francia en 1525, tras la batalla de Pavía ${ }^{35}$, quedando recogidos en el texto abundantes detalles sobre su estancia en esta ciudad, afirmando que su prisión tuvo lugar en el alcázar madrileño, tal como se dice también en las Batallas y Quinquagenas, y no en la torre de los Lujanes $^{36}$, siendo desarrollado este episodio más por extenso en una obra monográfica

${ }^{31}$ Gerbi, Antonello: La naturaleza de las Indias nuevas. De Colón a Gonzalo Fernández de Oviedo, México, 1978, pp. 160-170

${ }^{32}$ Este es el caso, sobre todo, de hechos acaecidos en Bolonia, Roma y Nápoles.

33 "Finalmente, andando así partió dende la çiudad de Plazençia para yr a Seuilla, y en Madrigalllejo, un lugar çerca del nombrado y deuotissimo monesterio de Guadalupe, de la orden de sant Gerónimo a veynte y dos de enero de mill e quinientos e diez e seis años dexó usar desta vida presente y dio el alma a Dios auiendo primero resçibido los sacramentos ecclesiásticos muy deuotamente en hedad de sesenta años y quatro años de su nasçimiento menos dos meses y [espacio en blanco] días, después que reynó en Castilla y Aragón quarenta años. Cuya alma tome reposo con Dios, que nadi de los reyes antepasados fue más justo en piedad ni de mayor gloria en las armas y batallas". BL-MS., fols., 38rv.

${ }^{34}$ Ballesteros, p. 97.

${ }^{35}$ Ballesteros, pp. 144-145.

${ }^{36}$ BL-MS, fols., 59v-60v. Numerosos autores tardíos a los acontecimientos situaron sin fundamento la de Francisco I en la torre de los Lujanes. Entre ellos se cuentan Lope de Vega, Gil González Dávila, Jerónimo de la Quintana, Claudio Climent o Alonso Suárez de Alarcon, entre otros. Por el contrario, esta 
dedicada por Oviedo a este asunto, ya en $1535^{37}$. Fernández de Oviedo seguirá a la corte a Toledo, aludiéndose en el manuscrito a la solemne entrada que tuvo el rey en esta ciudad el 27 de abril de 1525, "donde fue su magestad reçebido con más cuydado y gasto y número de gente que en ninguna otra ciudad"38. Del mismo modo, También se encontrará en la corte entre 1530 y 1532, año este último en que hará entrega a la emperatriz Isabel de Portugal de la primera parte del Catálogo real en el transcurso de las cortes celebradas en Medina del Campo, a la vez que obtiene el cargo de cronista de Indias el 18 de agosto de $1532^{39}$. Precisamente los acontecimientos acaecidos en la corte en 1532, bajo la autoridad de la emperatriz, en ausencia del emperador, se encuentran entre los episodios más prolijamente descritos en la obra, aludiendo a la marcha de la corte desde Granada hasta llegar a Medina del Campo ${ }^{40}$. A la corte había acudido Oviedo con fines de promoción política, al pretender la gobernación de Cartagena de Indias, que no logrará ${ }^{41}$, a la vez que hace entrega de la primera parte de su Catálogo Real a la emperatriz, como ya se ha dicho.

Múltiples relaciones personales que fueron especialmente decisivas en su vida están referidas a personajes que tienen una presencia muy relevante en el manuscrito. Este es el caso,en particular,de los siguientes personajes.

La emperatriz Isabel de Portugal, que fue una de sus principales valedoras en la corte, se encuentra, sin duda, entre estas relaciones personales especialmente decisivas. Hay partes de la crónica en que el interés del cronista está sobre todo monopolizado por seguir los avatares de la corte de la emperatriz, de la que da noticias muy directas que parecen ser vividas en primera persona, o bien ser resultado de las informaciones recibidas a través de quienes tenían gran proximidad con la emperatriz ${ }^{42}$. Hace una muy pormenorizada descripción de los miembros de la cámara de la emperatriz $^{43}$. De hecho, se maneja y se copia en el texto del manuscrito correspondencia enviada o recibida por la emperatriz. Es posible, además, que contase con especial

ubicación del monarca francés en el alcázar real es igualmente recogida por MexíA, Pedro, Historia del emperador Carlos V, edic. de J. de M. Carriazo, Madrid, 1945, p. 395.

${ }^{37}$ Fernández de Oviedo, Gonzalo: Relación de lo sucedido en la prisión del rey Francisco I de Francia, Colección de documentos inéditos para la historia de España, XXXVIII, Madrid, 1861. La versión manuscrita en Biblioteca Nacional de España, Ms. 8.756.

${ }^{38}$ Ibid., fol. $60 \mathrm{v}$.

${ }^{39}$ Fabregat Barrios, Santiago: “Gonzalo Fernández de Oviedo y Valdés (1478-1558). Entre dos edades y dos mundos" en Fernández de Oviedo, Gonzalo, Libro de la Cámara Real del Príncipe Don Juan, oficios de su casa y servicio ordinario, edic. de S. Fabregat Barrios, Valencia, 2006, p. 24.

${ }^{40}$ Ibid., fols. $87 \mathrm{v}-89 \mathrm{r}$.

${ }^{41}$ Oтте, Enrique: "Una carta inédita de Gonzalo Fernández de Oviedo", Revista de Indias, 65 (1956), pp. 437-458.

${ }^{42}$ Tras la marcha de Carlos de Granada en diciembre de 1526, la emperatriz, que estaba preñada, saldría algunos días más tarde para dirigirse a Granada y luego a Toledo, perdiendo atención el narrador hacia los movimientos de Carlos para dedicarse enteramente a narrar los movimientos de la corte de la emperatriz (BL-MS., fol. 66v). Teniendo en cuenta que sabemos cómo Fernández de Oviedo se había embarcado de vuelta para América en abril de 1526, cabe pensar que dispondría de algún informante en el círculo de la reina que le mantendría al día de los acontecimientos, tal como sucede cuando se refiere a las cortes celebradas en Valladolid en 1527 y cuando nace el 21 de mayo de 1527 el príncipe Felipe en Valladolid (fol. 66v).

${ }^{43}$ BL-MS, fol. 69rv. 
información a través de la amistad de Oviedo con Francisco de Zúñiga y Avellaneda, conde de Miranda, y mayordomo mayor de la emperatriz ${ }^{44}$.Algunos detalles de los movimientos de la corte de Isabel en su viaje desde Granada a Medina del Campo antes aludido bien podrían permitir sospecharlo.

Entre otros personajes con presencia destacada en el relato y con relación conocida con Fernández de Oviedo se contarían don Fernando, duque de Calabria ${ }^{45}$, Antonio de Leyva ${ }^{46}$, Gonzalo Fernández de Córdoba ${ }^{47}$, respecto del que abundan los elogios ${ }^{48}$, o Sancho de Castilla ${ }^{49}$, sobre el que llama la atención que destaque el autor del manuscrito a fecha de 1522 que había sido ayo del príncipe don Juan, muerto veinticinco años antes, de no tratarse precisamente de Fernández de Oviedo el que hace tal

${ }^{44}$ Francisco de Zúñiga y Avellaneda, conde de Miranda, «uno de los señores que en nuestro tiempo tuvo mucho crédito en la Casa Real». Era persona influyente en los círculos cortesanos del emperador. Fue nombrado por Carlos mayordomo mayor de la emperatriz Isabel de Portugal. A Francisco de Zúñiga dedica Oviedo un diálogo de sus Batallas y Quinquagenas. Fernández DE Oviedo, Gonzalo: Batallas y quinquagenas, edic. de J. Pérez de Tudela y Bueso, I, Madrid, 1983, pp. 159-176.

${ }^{45}$ Gonzalo Fernández de Oviedo estuvo al servicio del duque de Calabria entre 1502 y 1512, y mantuvo una continuada relación a lo largo de su vida. Algunos de los datos que se manejan en el manuscrito sobre la política italiana bien pudieran haber sido conocidos por el autor por medio de este personaje.

${ }^{46}$ Antonio de Leyva, capitán general de los Tercios, príncipe de Ascoli, conocido de Gonzalo Fernández de Oviedo, al coincidir con él cuando se hallaba al servicio del Duque de Calabria en 1503, toma una presencia central en la narración de los años 1529 y 1530, tras la entrada del emperador en Bolonia, lo que hace pensar que hubiera podido ser su fuente para la extensa descripción que hace de aquel acontecimiento en el que se da protagonismo principal a dicho personaje. BL-MS., fols. 75r-82r. Resulta interesante cotejar las referencias a esta ceremonia y a su intervención en ella de Antonio de Leyva tal como se recogen en AvalLE-Arce, pp. I, pp. 240-241.

${ }^{47}$ Gonzalo Fernández de Córdoba, es aludido en el manuscrito como de méritos iguales a los de Aníbal o Julio César (BL-MS., fol. 17v). Del Gran Capitán fue Gonzalo Fernández de Oviedo secretario en 1512, abundando las noticias en el texto sobre su actividad militar. "E quasi al cabo de su vida del Gran Capitán yo fuy secretario deste memorable señor, hasta quel año 1512 se fue rretraer a Loxa, quando se tractaua de boluer a Italia tercera vez". Avalle-Arce, Juan Bautista: Las memorias de Gonzalo Fernández de Oviedo, Valencia, 1974, I, p. 245.

48 "Y a esta causa fue ymbiado Gonçalo Fernández de Córdova, vellicoso cavallero, hombre muy experto en las cosas y exerçiçio de la guerra. Este Gonçalo Fernández es por aliquid di Terranova yntitulado y este noble varón, con algún número de caualleros y gente de pie, pasó resistir al rey de Françia la entrada de Çiçilia, y para que diese ayuda al rey Fiderico de Nápoles por donde me paresçe que si en nombre de los númidas, según escribe Salustio, fue por juzgar en España, renobado, quanto de mayor gloria deue el renombre de España ser nombrado en Ytalia y Çeçilia, y en todo el mundo, por los memorables fechos de este extremado y exçelente cauallero".BL-MS., fols., 16rv.

${ }^{49}$ Con motivo del viaje de Carlos a España en 1522 se da noticia sobre cómo el 5 de agosto el emperador se aposentó a su paso por Palencia en casa de "Don Sancho de Castilla que fue ayo del príncipe don Juan, tío de parte de madre de su muger" BL-MS., fol. 54v. En esa fecha, estaba Fernández de Oviedo en América, por lo que pudo haber tenido noticia de este hecho por carta del propio Sancho de Castilla con el que tenía antigua amistad puesto que había coincidido con él siendo mozo de cámara del príncipe don Juan, en cuyo Libro de la Cámara se puede leer: "Después que Johan Çapata murió, tuvo el mismo cargo don Sancho de Castilla, señor de Herrera de Valdecañas, que fue uno de los diez cavalleros diputados para la ordinaria compañía de la persona del prínçipe, los çinco ançianos e los çinco mançebos, pero nobles todos ellos; e mandó la reina que nunca faltase uno o dos de los más viejos, allende del ayo, estando o no estando Johan Çapata presente con el prínçipe. Éstos eran el dicho don Sancho de Castilla, que por su edad e loable ançianidad era el primero".FERnÁndEz DE Oviedo, Gonzalo: Libro de la Cámara Real del Príncipe Don Juan, oficios de su casa y servicio ordinario, edic. de S. Fabregat Barrios, Valencia, 2006, p. 88. 
evocación, del que sabemos había trabado amistad con el citado Sancho de Castilla precisamente durante su época al servicio del mencionado príncipe.

Hay acontecimientos especialmente relevantes en la biografía de Gonzalo Fernández de Oviedo que tienen una presencia destacada en el conjunto de la narración.

La muerte del príncipe Juan fue, sin duda, uno de los acontecimientos más decisivos en su trayectoria biográfica, contribuyendo a marcar el rumbo de su vida, cuando esta parecía destinada a un placentero acomodo cortesano: "allí se acabaron las esperanças que yo esperaua e me ofrescía esta vida. Por lo qual mi descontentamiento me lleuó fuera de España a peregrinar por el mundo" ${ }^{50}$. Los términos de tribulación y desventura que se utilizan en la textualidad del manuscrito con relación a este fallecimiento parecen especialmente adecuados a su propia trayectoria biográfica tras este acontecimiento, convirtiendo la muerte del príncipe Juan en un hecho de una excepcionalidad catastrófica evidente:

Ovieron más estos reyes otro hijo que fue llamado don Juan, que hera prínçipe de Asturias y de Girona este príncipe don Juan subçedía en estos reynos de Castilla y Aragón hera varón de muy excelentes costumbres, siguiendo y asimilando las mismas pisadas de sus padres, caso con doña Margarita, hija del rey de los romanos y en el primer año que casado fue, murió en la çiudad de Salamanca, llamó le Dios para su reyno por las maldades y pecados deste pueblo. En España dio su muerte mayor dolor, perdida tribulaçión y desventura que jamás dio muerte de prínçipe, y con gran razón. Dexó preñada a su legítima muger, la prinçesa doña Margarita, la qual morió antes que el convenible tiempo de su parto llegase" ${ }^{" 1}$.

La campaña de Salses, o Salsas, forma léxica bajo la que es aludido este lugar tanto en el manuscrito como en el Libro de la Cámara ${ }^{52}$ o como en Batallas y Quinquagenas $^{53}$, durante la guerra del Rosellón ${ }^{54}$, conoció la participación de Fernández de Oviedo ${ }^{55}$, siendo atendido el relato de este hecho en el texto con detalle muy notable en comparación con otros acontecimientos descritos, y haciendo una valoración muy encomiástica hacia el comportamiento de las fuerzas militares españolas ${ }^{56}$. Tal

${ }^{50}$ Avalle-Arce, Las memorias, II, p. 543.

${ }^{51}$ BL-MS, fol. $15 \mathrm{r}$.

52 "Ya yo vi lo mismo el año de 1503 en el campo del rey Católico, donde era capitán general don Fadrique de Toledo, duque de alva, quando huyeron los françeses que tenían çercada a Salsas". FERNÁNDez DE Oviedo, Gonzalo: Libro de la Cámara Real, ed. cit., p. 152.

${ }^{53}$ Batallas y quinquagenas, edic. cit., II, pp. 353-354.

${ }^{54}$ Para el contexto de este hecho véase: LAdero Quesada, Miguel Ángel: Ejércitos y armadas: Nápoles y el Rosellón (1494-1504); Madrid, 2010.

55 "Yo estuve esta noche en el campo y tuve creído, según las disposiciones de aquel paso estrecho en que los franceses estaban, entre la montaña y los estraños de agua slada, que pocos franceses salieran de allí con las vidas", Batallas y quinquagenas, II, p. 354.

56 "Después de auer muerto en çiertas vatallas que uvo más de veyntemill franceses y otros muchos que en Françia despojados volvieron doliéndose dello, tornó a ymbiar otro exérçito de guerra no menor que el primero para çercar a Salsas, fortaleza muy singular que está situada en las postreras partes y términos de España, y estos françeses pusieron su real y la çercaron peleando fuertemente por ganarla, más los que estavan en la fortaleza se defendieron muy fuertemente, matando muchos delos françeses que en el real estauan. Estonçes el rey don Fernando, que en Barçelona se halló con gran gente que la serenísima reyna doña Ysabel su mujer de Segovia le ynbio, fue contra los franceses, los quales oyendo cómo el rey con gente contra ellos yba, alçaron el çerco y real que sobre Salsas tenían puesto y dieron a 
atención en comparación con otras batallas de mucha mayor importancia histórica que aparecen aludidas en el texto se hace difícilmente comprensible de no darse la circunstancia de esa presencia personal del autor que eso escribe.

Fernández de Oviedo asegura en uno de sus relatos cómo fue testigo directo de la muerte de Isabel la Católica ${ }^{57}$. Pues bien, en el manuscrito la descripción que se hace de la muerte de la reina no parece corresponder al mero criterio cronístico de dar noticia de un acontecimiento relevante para la historia del reino, sino que se señalan circunstancias que buscan comunicar la actitud de la reina, así como las que se dan en torno a la cámara de la difunta, a lo que se añade el afán por precisar la hora exacta del deceso:

"Sobrevino rezia enfermedad corporal a la reyna doña Ysabel y opremidas y agrabiadas las femeninas fuerças desta cristianíssima reyna, estuuo por espaçio de çient días continuos de grande enfermedad fatigada. Y como en la yglesia de Dios por su salud muchas oraçiones, ayunos y sacrefiçios fechos fuesen y por juyzio oculto poco aprovechasen, viendo la excelentísima reyna que el tiempo que a su vida estaua por Dios determinado se açertava, mandó que de rogar a Dios por su salud corporal los ecclesiásticos çesasen y fuese por la salud de espiritual que los sacramentos eclesiásticos traydos les fuese. Hera tanta su honestidad y tan grande la observançia de su pudiçiçia (sic) que al tiempo que la extremaunçión le fue dada, ningún miembro suyo quiso que fuesse visto, sino de solo el saçerdote, ningún criado o criada de su real casa gelo viese. Hizo su testamento tan hordenado y marauilloso que casi divino se puede dezir. La gouernaçión destos sus reynos que dexava a su marido el rey don Fernando enconmendó encargando y pidiéndole que las rentas de su corona real no enajenase.

Y (a)cabó sus dias, la exçelente reyna doña Ysabel, honra de las Españas, espejo de las mugeres, en la villa de Medina del Campo, a veynte y seis días del mes de noviembre, año del señor de mill e quinientos e quatro años, entre las honze y doze del día, más çerca delas doze horas" ${ }^{\prime 58}$.

Esta presencia en el entorno de la reina cuando se produce su deceso probablemente sea lo que justifique la inclusión en la pequeña colección documental que sigue a la narración de los hechos de un documento ya antes aludido que, carente de interés por su tema con relación a los asuntos tratados, en cambio,se completa con una información que sólo podía conocer quien estaba presente en el desarrollo de los últimos momentos de la reina, señalando la simultaneidad de estos últimos momentos de la reina con una reunión del Consejo Real motivada por la urgencia de dar solución a un sentimiento de injusticia manifestado por la reina referido a un asunto de índole hacendística, volviendo el autor a hacer de nuevo referencia al instante preciso de la muerte de la reina en coincidencia con lo ya señalado en el texto del relato ${ }^{59}$.

fuyr siguiéndolos el rey con su gente de guerra, fueron en el alcançe fasta dentro de Françia, quemando y destruyendo todos los logares que en el camino estauan, salvando las vidas de los hombres que por misericordia su alteza mouido mandó que ningún françés sus gentes matasen". BL-MS, fols. 17v-18r.

57 "Sé yo muy bien e como testigo de vista, que de su muerte, que fue en Medina del Campo...", Avalle-Arce, p. 468.

${ }^{58}$ BL-MS, fol. 20rv.

59 "Esta carta se leyó con el presidente y los del consejo por el secretario Juan López, a XXI días del dicho mes de nouiembre de mil e quinientos e quatro años. Testigos que la oyeron leer e vieron publicar en el consejo el alcalde Gonzalo Ferrández Gallego e el licenciado Polanco, alcalde de la corte y el 
Distintos autores coinciden en situarlo en el séquito de Fernando el Católico en los años inmediatos a la muerte de Isabel ${ }^{60}$, lo que permite que se encuentre presente en las Cortes de Toro de 1505, cuando recibe de boca del rey el encargo del Catálogo Real, situándolo también en la entrevista que mantiene Fernando con su yerno Felipe, en Remesal, cerca de Sanabria ${ }^{61}$, cuando este ha entrado con manifiesta hostilidad hacia su suegro y acompañado de importante fuerza armada. Situada la entrevista en el 20 de junio de 1506, en la citada aldea de Remesal, en el manuscrito se le da como fecha al encuentro personal entre ambos monarcas el 19 de junio, escribiéndose como nombre del lugar Rreuiesa, mostrando con gran sutileza en el relato de los hechos la tensión entre ambos personajes:

En este tiempo ovo çiertas diferençias e contiendas entre el rey don Fernando e rey don Felipe, su yerno. Fue tal asiento fecho y dada esta concordia con los embaxadores que entre estos reynos entendían que ambos juntamente reynasen, poniendo a esto çiertas capitulaciones, las quales de guardar así el rey don Fernando, como el embaxador del rey don Felipe, que en Castilla estaua, con sus propias manos juraron dende a poco tiempo, pasando el rey don Felipe y la reyna doña Juana con gran flota que traya, pasaron en España, y en el mes de abril, año del señor de mil e quinientos e seis años aportaron en el reyno de Galizia, en la ciudad de La Coruña. En tierra salieron a cuyo recebimiento, fueron muchos grandes del reyno y algunos afirman que por ynduzimiento y consejo de algunos dellos fueron deshechas y rotas todas capitulaciones que entre estos reyes ante juradas y puestas estauan, y el rey don Felipe, con gran compaña de gente armada que consigo traya, salió del reyno de Galizia, entrando en Castilla, y el rey don Fernando le salió a resçebir pacíficamente, a diez y nueve días del mes de junio del dicho año. Vieron de entrambos estos reyes junto cabo la aldea de Rreuiesa, estando muy pocos presentes y muchos de lexos mirandola habla que estos reyes tovieron y después dese aver hablado, paresçió comúnmente ser visto a todos que la filial reuerençia por el rey don Felipe acerca de su padre como conuenía no serle guardada.

Fernández de Oviedo se encontraba de regreso en España, arribando el 5 de noviembre de 1523 a Sanlúcar, no regresando a América hasta abril de 1526. Son estos años en los que la narración del manuscrito se enriquece en cuanto a su nivel informativo con relación a las actividades dentro de la corte. Fernández de Oviedo había venido a España en busca de justicia, tras su enfrentamiento con su gran enemigo Pedrarias Dávila ${ }^{62}$. Esto suponía moverse entre la Audiencia Real y el Consejo Real. Por ello se dirigiría desde Sevilla a Burgos y luego a Vitoria, donde se hallaba el emperador, dispuesto a defender su causa, lo que le llevaría incluso a tener audiencia con el propio emperador ${ }^{63}$. Es llamativo que en la narración del manuscrito se

licenciado francisdo de Bargas, teniente de contador mayor de sus altezas. Y fue a la mañana a las diez. La reyna doña Ysabel spiró cerca de las doze de mediodía". BL-MS., fol. 121r.

${ }^{60}$ Ballesteros, p. 74; Amador de los Rios, José: "Vida y escritos de Gonzalo Fernández de Oviedo y Valdés", estudio introductorio de su edición de la Historia general y natural de las Indias, Madrid,1851-1855, p. XXI

${ }^{61}$ Bernáldez, Andrés: Historia de los Reyes Católicos, Biblioteca de Autores Españoles, LXX, Madrid, 1953, p. 725; Villapalos, Gustavo: Fernando V (1474-1516), Palencia, 1998, pp. 255-256.

${ }^{62}$ Mena García, María del Carmen, Pedrarias Dávila, Sevilla, 1992.

${ }^{63}$ Ballesteros, pp. 139-140. 
concentre para 1523-152464 la atención en lo que es el ejercicio de la justicia, reclamando el papel supremo que debe tener ésta, atendiendo a la actividad del Consejo y la Audiencia reales e incluyendo una hiperbólica alabanza de la rectitud y virtudes, especialmente religiosas, del emperador y señalando el papel personal que el emperador debía ejercer en materia de justicia, sustituyendo la mera técnica de narración de los acontecimientos por otra que respondía más bien a un criterio especular en el que se busca ejercer alguna forma de pedagogía política, poniendo de relieve lo que debe ser el comportamiento ejemplar de un monarca en materia de justicia, tema que precisamente acuciaba a Fernández de Oviedo por aquellos días:

$\mathrm{Y}$ en tanto es el emperador y çelador de la justicia que a todos los juezes, corregidores y presides y delegados dize y amonesta, que no desuíen de la re(c)ta uía y balanca (balanza) de justicia, aunque piensen que le harían placer a él en ello, por que no se huelga más en cosa que en hazer justicia, no es ya que tardar contando sus virtudes sería obra y trabajo sin medida no ygual a la poquedad de mi yngenio, tales que començando fallesçería, especialmente que yo començé a escribir y tomar la pluma de poner en memoria algunas cosas dignas que no meresçien oluido" ${ }^{65}$.

Son estos años también de 1524 a 1526 especialmente ricos en informaciones referentes a los personajes que se mueven en la más elevada esfera política de la corte y donde se da abundante noticia de nombramientos, fallecimientos y sucesiones dentro de ese círculo.

No reiteraré lo ya señalado para el periodo 1530-1532, de nuevo en la corte, años para los que la narración experimenta un notable enriquecimiento de información con respecto al medio cortesano en el que precisamente se está desenvolviendo el escritor madrileño por esas fechas.

La interrupción, que no probablemente finalización del texto, si se tiene en cuenta los documentos que lo siguen, se produce de una manera que bien puede calificarse como de abrupta y repentina. Esto podría conectarse con un acontecimiento relevante de la vida de Fernández de Oviedo, pues si esta interrupción se produce a fines de 1536, aunque apenas nada se relata de este año, habiendo quedado, en realidad, terminada la narración con los acontecimientos de 1535, tras la victoriosa toma de La Goleta y las consiguientes celebraciones que en honor al emperador tienen lugar, en especial en Nápoles ${ }^{66}$, también ese año trae consigo para nuestro personaje un tristísimo acontecimiento que acaso resultase determinante en el propio devenir del texto. En efecto, hallándose en La Española, recibe la noticia de la muerte de su único hijo varón, Francisco González de Valdés, que contaba veintisiete años, como consecuencia de su ahogamiento al atravesar el río Arequipa mientras participaba en a expedición de Diego de Almagro, muriendo también aquel mismo año uno de los dos huérfanos que dejaba el hijo recién finado ${ }^{67}$. Estas circunstancias han sido consideradas como motivo para que el autor de la Batallas y quinquagenas quedara sumido

\footnotetext{
${ }^{64}$ BL-MS., fols. 56r-57r.

${ }^{65}$ Ibid., 56v-57r.

${ }^{66}$ BL-MS., Fols. 113r-118v.

${ }^{67}$ Ballesteros, p. 159.
} 
en un "profundo bache espiritual" que produciría un paréntesis en el desarrollo de su prolífica obra ${ }^{68}$.

\section{LA OBRA DE GONZALO FERNÁNDEZ DE OVIEDO EN SUS CONEXIONES CON EL MANUSCRITO}

Cabe establecer distintas conexiones entre BL-MS y, al menos, cinco de las obras más relevantes de Gonzalo Fernández de Oviedo, pudiendo extraer de algunas de ellas datos precisos que harían más comprensible la razón de ser del propio manuscrito.

El Catálogo Real. En esta obra ${ }^{69}$, en su primera parte, única conocida en su textualidad, en la que se traza una historia de los reyes de España que va desde Túbal hasta Juan II de Castilla, se puede leer lo siguiente en su proemio:

Con lo ques dicho se dará la final conclusión a esta primera parte o libro deste apostólico e del Real Catálogo, porque en el segundo volumen se tratará desdel rey don Enrrique, quarto rey de Castilla, e desdesdel [sic] rey don Johan de Aragón hasta el rey don Juan de Navarra, que perdió aquel reyno, hasta el Rey Cathólico don Fernando que ganó a Granada e a Nápoles. E después en su lugar se porná la relaçión sumaria de lo que tocare a la Çesárea Magestad del Emperador Rey, nuestro señor don Carlos, quinto de tal nombre, con el qual se acabarán de resumir todas las líneas de los rreyes de Castilla e de Aragón e Nápoles e de Navarra, e los duques de Borgoña e de los condes de Flandes, e de los condes de Holanda e de los emperadores, aviendo tanbién primero memorado el árbol de la rreal consagujnidad de los rreyes de Portugal, desde donde en esta parte çesaré hasta concluyr en el serenísimo rrey don Johan, que al presente reyna en Portugal" 70 .

En la misma obra se dice:

"La presente es desde el primero Rey de España hasta en fin de la vida del Serenísimo rey don Johan, segundo de tal nombre en Castilla, bisabuelo de Vuestra Magestad Carlos, con los otros reyes de Nauarra y Aragón e Portugal. E la segunda parte ha de ser desde allí hasta el tiempo presente" $"$.

Esta obra fue redactada en esta primera parte entre 1518 y 1532. Por tanto, su intención queda clara: escribir una continuación del Catálogo Real que empiece con el reinado de Enrique IV y llegue hasta, al menos, ya entrados los años 30 del siglo XVI. Su planteamiento como, mejor que crónica, memoria abreviada de reinados por orden cronológico sería enteramente coincidente con el manuscrito londinense que, de acuerdo con esta descripción de contenidos y con el modo de afrontar el relato de los reinados, bien podría ser el texto que se anuncia en el fragmento que se acaba de reproducir. Así, acabada la primera parte, este manuscrito, desde ese punto de vista,podría venir a suponer la anunciada segunda parte, arrancando desde el final del

\footnotetext{
${ }^{68}$ Pérez de Tudela y Bueso, p. XXIV.

${ }^{69}$ Véase Romano de Thuesen, antes cit.

${ }^{70}$ Biblioteca del Real Monasterio de San Lorenzo de El Escorial, H.I.7, fol. 398v; Romano de ThueSEN, p. 1.697.

${ }^{71}$ Romano de Thuesen, , p. 43.
} 
reinado de Juan II y llegando con redacción continua hasta 1536, a lo que se añaden materiales documentales con los que se pretendía completar detalles de lo ya escrito en esa segunda parte y preparar su continuación hasta alcanzar hasta el año $1542^{72}$. Precisamente, en la noticia que da de la terminación de la primera parte del Catálogo Real, se sitúa el propio Fernández de Oviedo como estando en Medina del Campo el último día de abril de 1532, siendo en ese momento cuando hace entrega personal de la primera parte del Catálogo Real a la emperatriz y en el contexto de su segundo intento por alcanzar la condición de cronista real que ya había pretendido en 1524, cuando había fracasado al ser elegido para el cargo el reputado humanista fray Antonio de Guevara ${ }^{73}$. Estaba, por tanto, acompañando a la corte de la emperatriz como encargada de la gobernación del reino en ausencia de Carlos, dando en el manuscrito noticias de cierto detalle sobre la situación en la corte que llegan incluso a ofrecer reflejo textual de la correspondencia que le llegaba a la emperatriz de Carlos, aludiendo a cómo se convocaron cortes en esa villa de Medina el 5 de agosto de ese año, a cuya celebración alude con alguna extensión ${ }^{74}$.

Epílogo Real, Imperial y pontificio. Esta obra inédita y conservada bajo forma de Minutas, tal como se dice en el propio texto, en un manuscrito único en la Biblioteca Nacional de Madrid, por tanto, en versión resumida ${ }^{75}$, constituye un texto de imposible edición como consecuencia de la caótica acumulación de notas marginales en letra de ínfimo tamaño y el mal estado de la tinta que hace extremadamente difícil, cuando no impracticable, su lectura continuada. Teniendo un comienzo bastante cuidado y de apariencia solemne, con abundantes dibujos de escudos de armas, pronto pasa a tener la apariencia de un borrador apresurado. Parece haberse elaborado a partir de 1535, según se indica en su primera página, alcanzando las noticias más tardías que contiene hasta 1542. Se trata del intento de hacer una especie de inventario de reyes, emperadores y papas, siendo más detallado con relación a los reyes españoles; incluyendo apenas una relación con nombres y fechas para los que no pertenecen al ámbito hispánico. Arranca también, como el Catálogo Real, en su primera parte, desde Túbal y llega hasta Carlos V, hasta la mencionada fecha de 1542. No deja de ser llamativo que tanto el Epílogo, como el manuscrito londinense tengan por último referente cronológico el año 1542.

Del mismo modo, tanto en el Epílogo como en el manuscrito, aunque, en este caso con trazo más imperfecto, se comprueba que el nombre de cada monarca aparece rodeado de un círculo al comienzo del capítulo correspondiente.

Siendo una obra mucho más breve de contenidos, para lo que se refiere al periodo 1454 a 1536 que se aborda en el manuscrito, bien hubieran podido ser utilizadas las informaciones incluidas en este como material a resumir en las Minutas del Epílogo. En efecto, para la parte correspondiente a lo que va desde Enrique IV en adelante,

${ }^{72}$ «E lo acabé en Medina del Campo el postrero día de abril de mill e qui- nientos e treinta y dos años: plega a Jhesucristo que a su serviçio y alabança y para gloria y honor de España sea todo lo que está dicho y que me dexe sacar en limpio la segunda e terçera parte», Catálogo Real de Castilla, Biblioteca de El Escorial, ms. H.I.7, fol. 427.

${ }^{73}$ Kagan, Richard L.: Los cronistas y la Corona. La política de la historia de España en las edades media y moderna, Madrid, 2010, p. 109.

${ }^{74}$ BL-MS., fol. 87v.

${ }^{75}$ Biblioteca Nacional de Madrid, Ms. 6.224. 
a partir de las catas que he podido hacer, si no he hallado coincidencias textuales, sí hay una evidente correspondencia de temas y puntos de vista con lo recogido en el manuscrito. La caracterización de personajes, la sucesión de acontecimientos y la selección de los mismos permitirían, en efecto, hacer pensar que estas Minutas del Epílogo son, para el periodo considerado, un apretado resumen de lo que se recoge en el manuscrito, aunque con gran diferencia de extensión ya que, habitualmente, en ellas se viene a resumir en unas pocas líneas lo que en el BL-MSse desarrolla en varios folios, ofreciéndose la siguiente correspondencia:

Fol. LXXXIIv-LXXXIIIr (Enrique IV) del BL-MS; fol. 1r -8v de las Minutas del Epílogo.

Fol. LXXXIIIv-LXXXVr (Reyes Católicos hasta muerte de Isabel) del BLMS; fol. 8v-20v de las Minutas del Epílogo.

Fol. LXXXVr-LXXXVv (1504-1516) del BL-MS; fol. 21r-39r de las Minutas del Epílogo.

Fol. LXXXVv-XCIIIv (Carlos V) del BL-MS; fol. 39r-118v de las Minutas del Epílogo.

Así, por tanto, lo que en el Epílogo se abarca en 11 folios, en el BL-MS se hace lo mismo en 118 .

El propio título de Epílogo tendría sentido como breve sumario realizado al término de la segunda parte del Catálogo Real.Por ello, podría ser aceptada la opinión de Fabregat al señalar: "ya apuntamos en un trabajo anterior que, a nuestro juicio, ambos textos (refiriéndose al Epílogo y a las Batallas, junto al Catálogo real), podrían constituir, en realidad, partes distintas de una inmensa y monumental obra, que recogiese los reinados de todos los monarcas españoles desde el legendario Túbal hasta Carlos I"76. Bajo este planteamiento que respondería a un criterio de unidad del proyecto historiográfico del autor, la conexión para el periodo 1454-1542 entre el manuscrito londinente y el Epilogo se antoja particularmente estrecha. No parece, en cambio, correcto lo señalado en su día por Amador de los Ríos con relación a esta obra cuando afirmó que "el Epílogo imperial, real y pontifical (...) parece formar la segunda y tercera parte del Catálogo" "77.

Batallas y quinquagenas. En el manuscrito se hace presente un afán recopilatorio de personajes, cargos, nombramientos, decesos, como si estuviera presente en el autor una preocupación de acumulación de estos datos que están tan en la línea de lo que se encuentra en Batallas y quinquagenas. Pero más allá de esta circunstancia,esta obra ofrece algunos elementos de reflexión útiles con respecto a la posible vinculación del manuscrito aquí estudiado con la labor historiográfica de Fernández de Oviedo ${ }^{78}$.

En esta obra se afirma por Fernández de Oviedo:

${ }^{76}$ FABREGAT, pp. 94-95.

77 Amador de los Rios, José: "Vida y escritos de Gonzalo Fernández de Oviedo y Valdés", estudio introductorio de su edición de la Historia general y natural de las Indias, Madrid,1851-1855, p. XCI.

${ }^{78}$ Véase una referencia a ello en CARrillo CASTILlo, Jesús M.: Naturaleza e Imperio. La representación del mundo natural en la Historia general y natural de las Indicas de Gonzalo Fernández de Oviedo, Madrid, 2004, nota 93. 
Yo escreuí el Cathálogo de los rreyes de España e quise por sus quatro abuelos dezir al Emperador su prosapia. Y su Çesárea Magestad se quiso seruir de aquel tratado, que era de quinientas o más hojas de marca rreal y desta mi mano e letra, e allí dixe parte de lo que vi e alcançé de aquella bendita Rreyna a su nieto, el año de 1535 años, al tiempo que su magestad Cesárea se partió para África quando tomó La Goleta e a Túnez"79.

En efecto, el último acontecimiento que aparece tratado en el desarrollo narrativo del manuscrito es la toma de La Goleta, que es tratado con bastante pormenor, de modo que, aunque la narración avanza hasta llegar a terminar el año de 1536, de este año apenas relata en unas pocas líneas el regreso de Carlos V a España, entrando por Barcelona y hallándose el 14 de diciembre en Tordesillas, donde finaliza, si no contamos la colección de documentos que incluye seguidamente que llevan hasta 1542 . Así, por tanto, bien puede establecerse la toma de La Goleta como el gran hito final con que se cierra el trabajo ${ }^{80}$.

Con relación a esa referencia que hace a un manuscrito de 500 hojas o más, podría estar en el rango de extensión que vendría a sumar entre la primera y segunda parte del Catálogo Real, si tenemos en cuenta que el manuscrito escurialense que contiene la primera parte se sitúa en torno a los 450 folios y el londinense, en su contenido narrativo, 118.

Por otra parte, en Batallas se encuentra referencia a la muerte heroica y martirial, tal como se juzga por el autor, del "capitán y mártir sancto Martín de Vargas" 81 , de origen madrileño que también aparece recogida en el manuscrito ${ }^{82}$, lo que llama especialmente la atención si se tiene en cuenta su interés puramente local desde el punto de vista de lo que podría ser un autor madrileño con relación a un personaje, hijo de Iván de Vargas y de Mencía de Sotomayor, muerto a manos de Barbarroja en el peñón de Vélez, perteneciente, por tanto, a uno de los linajes más caracterizados de esta ciudad como era el de los Vargas.

Finalmente, también merece destacar la referencia elogiosa que hace hacia la obra cronística de Diego Enríquez del Castillo, crónica que tiene Fernández de Oviedo como "la mas cierta de todas las que deste Rrey se escriuieron" "83, observándose la estricta dependencia de lo que sobre Enrique IV se escribe en el manuscrito con relación a dicha crónica. Precisamente llama la atención la reiterada utilización de un calificativo especialmente característico para Enrique IV coincidente en Batallas y quinquagenas y en el manuscrito: "príncipe manso" 84.

Historia general y natural de las Indias. Aunque, dada la naturaleza de sus contenidos, no hay ninguna relación entre esta obra y el BL-MS, sí se encuentra en ella una noticia interesante para el asunto aquí tratado:

Después que de Monzón partió César [año de 1542], pasó en Alemania, y en aquellos sus estados que por allí tiene, le dio Dios los buenos sucesos que en la segunda

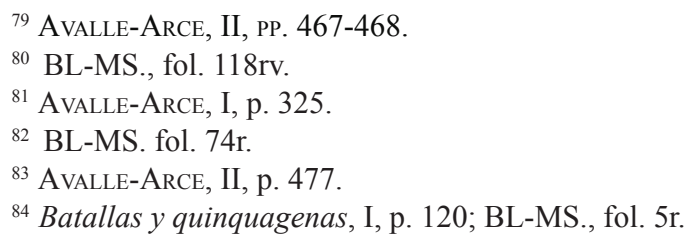


parte que escribí del Catálogo real de Castilla, dende el capítulo IV en adelante, podrá ver, entender e conoscer quien sano juicio toviere; y conoscerá la soberbia del rey Francisco de Francia, e la demasiado diligencia que, con todas sus fuerzas, ha usado para fatigar al mundo y los cristianos, en compañía e confianza del gran turco e sus infieles ejércitos, por mar y por tierra ${ }^{85}$.

Aunque en la narración del BL-MS no se alude a este hecho en cuanto que su narración continua se detiene en 1536, precisamente el documento más tardío que recoge el BL-MS es el referido a los acuerdos que se tomaron en las Cortes de Monzón de 1542 de cara a preparar una campaña contra Francisco ${ }^{86}$. La alusión al capítulo IV podría estar justificado porque en el BL-MS se distinguen cuatro partes (cuatro círculos de monarcas, Enrique IV, Isabel y Fernando, Felipe y Juana, Carlos) en función de los reinados, siendo la de Carlos $\mathrm{V}$ la cuarta.

De este modo, por lo que atañe a su terminación, lo contenido en el manuscrito sería compatible con las dos versiones contradictorias que da el propio Fernández de Oviedo con respecto al punto final de la segunda parte de Catálogo Real, pues, tal como se ha dicho, sería, en efecto, compatible con lo que dice el autor cuando sitúa el final hacia 1535, con la toma de La Goleta, pues es éste, en realidad, el último acontecimiento histórico relevante abordado en la narración, como lo sería también con la afirmación de que llega hasta las cortes de Monzón de 1542, pues es precisamente éste el acontecimiento más tardío recogido en el manuscrito, aunque no dentro de su desarrollo narrativo, sino dentro de la colección documental que incorpora y que hace sospechar que estaba en el pensamiento del autor llegar hasta dicho momento.

\section{EL PROCESO DE REDACCIÓN}

Contextualizando el manuscrito de la British Library en la obra de Fernández de Oviedo, cabría plantear la hipótesis de un proceso de redacción con una cronología que nos mostraría cómo dicho proceso no resultaría en absoluto nada lineal. Conviene, para ello, antes que nada, partir de dos consideraciones:el carácter problemático que tuvo para Fernández de Oviedo la redacción del reinado de Enrique IV y el significado determinante que para la redacción de la segunda parte del Catálogo Real tuvo la fecha de 1532, en que se produce la entrega a la emperatriz Isabel de Portugal de la primera parte, que va a implicar para el autor el compromiso de continuidad de lo entonces entregado y que sólo llegaba hasta terminar el reinado de Juan II.

Con relación al reinado de Enrique IV, el propio autor da contundente testimonio de su dependencia respecto de la crónica de este reinado escrita por Diego Enríquez del Castillo:

Son los coronistas de los rreyes muchos, y quanto ellos son más rremisos e de peor rrecabdo así tienen más escritores contra sí. Es verdad que sin muchos caualleros e hidalgos ancianos del tiempo del rey Enrrique 4 que le conoscieron e siruieron, fidedignos, a quien yo oydezir muchas cosas, e sin las crónicas de algunos de sus

${ }^{85}$ Historia general y natural de las Indias, libro xxxiii, cap. LIV, ed. Pérez de Tudela (1959: vol. IV, 258).

${ }^{86}$ BL-MS, Fol. 129r. 
historiadores, ha XXII años que yo vi una crónica deste Rey en la cámara de vno de los mayores señores de España, la qual escriuió el licenciado Diego Anrríquez [sic] de Castilla, coronista del Rrey y de su Consejo y su capellán. La qual se tiene por la más cierta de todas las que deste Rrey se escriuieron, e habla tan libremente que en sus palabras se conosce que escriuió como hombre limpio e apartado de fábulas ni lagoterías, sino conforme a verdad ${ }^{87}$.

Lo cierto es que, en ausencia de esta noticia, resultaba bien evidente la dependencia del texto del manuscrito en lo referente a este reinado con respecto a la obra del capellán enriqueño. Sin embargo, es de destacar que en esta confesión de Fernández de Oviedo se contiene un dato cronológico interesante que puede resultar muy valioso para intentar trazar una cronología del proceso de redacción cuando se señala que "ha XXII años" con respecto a la redacción del texto en el que eso afirma, es decir, la III Quinquagena que concluye en 1555. Así, por tanto, esto sería hacia 1533, es decir, inmediatamente después de la entrega de la primera parte del Catálogo. Este dato sería muy significativo a la hora de comprender el porqué el Catálogo, en su primera parte,no había ido más allá del reinado de Juan II. Sencillamente, porque el autor no había podido disponer de una narración aceptable, según su criterio, de los sucesos de ese reinado, de la que sí dispuso, en cambio, a partir de esta lectura de 1533. Esto, junto con otros datos que se irán viendo, me hace pensar en la siguiente cronología de redacción:

1490-1505. Recibe el encargo en las cortes de Toro de 1505 de redactar lo que será el Catálogo:

E porque desto se dirá más largamente en la segunda parte, aquí se concluye la primera destetractado e rreal Catálogo e sumario reportorio de los pontífiçes que ha avido en la Yglesja de Dios, de los quales mucho se pudiera en todo lo que se ha tocado escrevir, sino por no pervertir la orden con que me ofresçí a este trabajo, que como en otra parte se ha dicho començé estando el Cathólico Rrey don Fernando, qujnto de tal nombre, en la çibdad de Toro haziendo allj cortes, año del Señor de mjll e quinjentos e çinco años e le acabé en Medina del Campo el postrero día de abrjl de mjll e quinjentos e treynta e dos años"s8.

Cabe pensar que si recibe este encargo en las cortes de Toro, sin tener puesto conocido que justificase su dedicación a tal actividad habría de ser porque alguna destreza debía haber mostrado como autor de obra histórica. En este sentido, cabe llamar la atención sobre cómo el propio Fernández de Oviedo manifiesta lo siguiente:

Yo escribo desde que tuve edad para ocuparme en semejante materia, así de lo que pasó a España desde el año de 1490 hasta aquí" $"$.

Tal afirmación, junto con el encargo de 1505, hace pensar que la habilidad del autor para escribir sobre historia debía ser una cualidad que ya era conocida en la corte, lo que permitiría plantearse la posibilidad de que la parte correspondiente a los Reyes

${ }^{87}$ Avalle-Arce, II, p. 477.

${ }^{88}$ Biblioteca del Real Monasterio de San Lorenzo de El Escorial, H.I.7, fol. 427v

${ }^{89}$ FernándeZ de Oviedo, Gonzalo: "Sumario de la natural historia", en Historiadores primitivos de Indias, edic. de Enrique Vedia, Biblioteca de Autores Españoles, vol XXII, Madrid, 1946, p. 471. 
Católicos podría haberse empezado en su redacción en una fecha no muy lejana a 1490, divulgándose en la corte algo de su trabajo, siendo lo bastante valorado como para recibir tal encargo sin ser todavía autor de obra conocida relevante.

1516. Es evidente que hay un corte en la redacción del manuscrito entre 1516 y la llegada a España de Carlos V que posiblemente está relacionado con las propias dudas que el autor tiene con respecto a lo que habrá de ser el devenir político inmediato de la Corona, que ve con evidente inquietud personal, lo que hace que incluso se embarque con dirección a Flandes para tratar de tomar posiciones en un marco político cambiante cuyo futuro inmediato no ve claro, tal como se expresa al terminar 1516. En efecto, en ese punto de la redacción del manuscrito se lee lo siguiente:

Plega a Dios que por esto y sano y saluo venga el príncipe nuestro señor a tomar la posesión y gouierno de tales y tantos reynos que le están esperando y aparejados con toda bienauenturanza" $"$.

Con ello se estaría evidenciando que cuando esto escribía el autor no conocía lo que iba a acaecer. Con lo cual, en ese momento, podría tener redactado el reinado de los Reyes Católicos que habría podido comenzar en algún momento bastante próximo a las Cortes de Toro de 1505 en que recibe el encargo real de escribir una obra que responda a las características de lo que acabará siendo el Catálogo y que habría desarrollado con bastante proximidad a los acontecimientos que se van sucediendo, deteniéndose a la espera de los acontecimientos tras la muerte de Fernando el Católico.

1523. Me parece probable que, independientemente de los avances que hubiera podido dar a la primera parte del Catálogo tras la muerte de Fernando el Católico ${ }^{91}$, no retomase la redacción de la segunda parte dando comienzo a los acontecimientos de los primeros años del reinado de Carlos hasta una fecha posterior a la Guerra de las Comunidades, ya probablemente con motivo de su regreso a España en 1523, quizá ya en 1525 o 1526, momento en el que, además, relata la llegada de Francisco I a su prisión matritense con bastante cercanía a los hechos que describe y en que el panorama político comienza a despejarse, tras las recientes turbulencias, y puede centrar su atención en comenzar a trazar el perfil apologético de que rodeará la figura del emperador, al que ya puede mostrar como vencedor, tanto de los tumultos interiores, como del tradicional enemigo francés. Ya en ese momento podía, por ejemplo, abordar con seguridad la narración de una guerra de las Comunidades con la certeza de su evolución y efectos. Para entonces, podría estar bastante avanzada la redacción de la primera parte. Para cuando esta es entregada a la emperatriz, aceptando el compromiso de llevar adelante el relato de los hechos de los reyes hasta el momento actual,

90 BL-MS. fol. 38r.

${ }^{91}$ En una carta de Lope Conchillos de 19 de mayo de 1518 a Gonzalo Fernández de Oviedo, Conchillos le dice: "tengoos en merced la genealogía de los reyes de España que decís que me queréis enviar y yo ceo bien que ella es tal que contentaría a los que decís que la vieron”. Отте, Enrique: “Aspiraciones y actividades heterogéneas de Gonzalo Fernández de Oviedo, cronista”, Revista de Indias, XVIII (1958), pp. 9-61. Tal afirmación podría hacer pensar que se está refiriendo a la primera parte del Catálogo real. Sin embargo, me inclino a pensar que fuera una versión todavía no del todo completa ya que se hace extraño que si tenía acabada la obra en 1518 esperase a 1532 a entregarla al emperador en la persona de la emperatriz, mucho más teniendo en cuenta su presencia en la corte entre 1523 y 1526 y la necesidad que tuvo durante esta estancia de conseguir el apoyo del rey en su pendencia con Pedrarias Dávila. 
sabe que tiene un problema pendiente de resolución: ¿cómo abordar adecuadamente el reinado de Enrique IV para el que no cuenta con la información que precisa bajo forma de una crónica que sea de su pleno gusto?

1532. Entrega a la Emperatriz de la primera parte del Catálogo, coincidiendo con su presencia en las Cortes de Medina del Campo, contexto histórico que desarrolla con detalle en el BL-MS. En aquél momento ya tendría redactado el reinado de los Reyes Católicos, llegando hasta la muerte de Fernando el Católico.

1533. Busca información sobre el reinado de Enrique IV que no tiene resuelto hasta que, tal como nos permite conocer el testimonio antes reseñado del autor, consigue disponer de la crónica de Enríquez del Castillo, que es lo que en esencia está resumido con relación a este reinado en el BL-MS.

1533-36. Completa lo que le resta del reinado de Carlos V hasta la toma de La Goleta en 1535, que le permite concluir con una imagen de un Carlos V triunfante, recogiendo las celebraciones posteriores y dejando la obra interrumpida, aunque seguramente con intención de continuarla, en 1536, momento en el que, tras la muerte de su hijo, parece abandonar temporalmente la actividad redactora referente a proyectos de largo alcance para dedicarse a otros de menor envergadura en los años inmediatos.

1536-1542. Tras la interrupción de la segunda parte del Catálogo parece retomar su actividad historiográfica y memorialística mediante la elaboración de material complementario: el Epílogo imperial y el acopio de documentos que le podrían servir para ampliar detalles de la segunda parte del Catálogo y llevarlo más adelante en el tiempo. Estos trabajos menores también le podrían ser útiles para la elaboración de otro proyecto, el de las Batallas y quinquagenas. Así llegaría hasta 1542 en que posiblemente abandonó el trabajo en la segunda parte del Catálogo, que acaso no pasó de una versión provisional, no definitiva,tal como se refleja en el manuscrito, en espera de mejor momento.

\section{TEMAS Y PERSPECTIVAS}

Sin pretender hacer una relación completa de temas y perspectivas que tienen presencia relevante en el manuscrito londinense, sí se van a enumerar brevemente algunos que, ofreciendo una reiteración apreciable en el mismo, nos obligan a pensar en Fernández de Oviedo como alguien idóneo para asumir la autoría del texto, teniendo en cuenta su marcado interés por este tipo de asuntos, por cuanto se trata de temas y puntos de vista muy característicos dentro del resto de su obra.

La actividad bélica. Podría afirmarse que la actividad bélica está en el centro de los intereses del texto, percibiéndose que para el autor la valoración positiva o negativa de un monarca en gran medida está asociada a su mayor o menor éxito con las armas. Este interés por los hechos militares presenta, además, algunos rasgos característicos. Así, se observa una especial atención a los detalles de los hechos de armas, a las actitudes personales de los soldados participantes, a los aprovisionamientos de las tropas, con valoración de las estrategias y de las decisiones de jefes militares. Puede afirmarse que la actividad bélica es vista con los ojos de un profesional de las armas. Todos los que fueron los principales escenarios bélicos de la época están 
presentes: Granada, el Rosellón, Navarra, Italia, el norte de África. Es precisamente para el periodo 1500 a 1512 cuando el autor está especialmente atento a los hechos militares del momento, siendo esta la época que coincidiría con la mayor dedicación de Fernández de Oviedo a la milicia. Del mismo modo, los éxitos militares de Carlos V, tanto en Italia como en Túnez y Argel, se presentan con un carácter más selectivo, pareciendo resultantes en algunos casos de cartas y descripciones provenientes de protagonistas directos, tal como sucede con respecto a las celebraciones que siguieron a estos hechos de armas.

Ceremonias y fiestas cortesanas. Este tema se encuentra entre los que alcanza mayor desarrollo en el manuscrito para la época, en concreto, del reinado de Carlos V, teniendo una presencia desproporcionadamente grande en el contexto de los asuntos tratados. En todo momento se muestra muy atento el autor a la descripción de juegos de cañas, corridas de toros, torneos, vestuario ceremonial, símbolos ceremoniales... Sin estar presente en muchos de los eventos que trata, los describe con gran prolijidad, lo que demuestra disponer de excelentes informantes situados en pleno centro de los espectáculos aludidos ${ }^{92}$. Relieve especial en este apartado tiene la celebración de la conquista de La Goleta que tuvo lugar en Nápoles en 1535. Existiendo una narración de la gran entrada ofrecida a Carlos V por un testigo directo, Andrea di Sala ${ }^{93}$, la versión del manuscrito apenas nada tiene que envidiar, describiéndose pormenorizadamente el extenso conjunto de elementos decorativos y conmemorativos que se prepararon para la ocasión a lo largo de seis folios ${ }^{94}$, constituyendo una especie de apoteosis final en el desarrollo del itinerario victorioso que se presenta de Carlos V. Esto hace pensar, que, de tratarse de Fernández de Oviedo, dada su experiencia en la corte y en su práctica ceremonial, podría conservar contactos que le comunicasen por carta acontecimientos festivos en cuanto que era un tema que le interesaba, lo que le permitiría incorporar la descripción, a veces pormenorizada, de actividades de este tipo acaecidas durante su estancia en América. En consecuencia, según se va avanzando en el relato, el interés por la actividad militar se acompasa con la atención que se va prestando a los acontecimientos ceremoniales de la vida cortesana, en muchos casos resultado precisamente de victorias militares.

Los Reyes de Armas. Gonzalo Fernández de Oviedo habría tenido consideración, según alguno de sus biógrafos, de rey de armas honorario ${ }^{95}$. Su obra refleja, en este sentido, extenso y detallista interés por todo lo que afecta a las cuestiones propias

${ }^{92}$ Ver los referidos a los años 1516-19, en los que no parece probable que estuviera, pero que, en cambio, están extensamente descritos (fols. 39v-42r).

${ }^{93}$ SALA, Andrea, Il triompha leapparato per la entrada della Cesarea Maestà in Napoli et di Missina con el significato delli architriomphal et de le figure antiche in prosa et versi latini, s.1., 1535. Hay ejemplares del texto impreso en la Real Biblioteca del Monasterio del Escorial (sig. 17-V-49), así como en la Biblioteca Apostólica Vaticana, Biblioteca Moreniana de Florencia, Biblioteca Vallicelliana de Roma, Biblioteca Angelica de Roma, Biblioteca de la Provincia romana dei Fratidell'Ordine della Mercede de Roma y en la Biblioteca Marciana de Venecia. Con relación a las numerosas inscripciones que se recogen en el manuscrito londinense que se elaboraron con motivo de la entrada de Carlos V, hay ocasionales discrepancias de transcripción con las que presenta Andrea di Sala.

${ }^{94}$ De hecho, la importancia que se da a este acontecimiento hace que aparezca con título propio en el manuscrito: "Aparato triunfal hordenado en la ciudad de Nápoles en la entrada de su Magestad". BL-MS., fol. $112 \mathrm{v}$.

${ }^{95}$ Pérez de Tudela y Bueso, p. XVII. 
de la genealogía y la heráldica, campos característicos de la actividad de tal oficio, habiendo varios momentos de la narración en los que concentra especialmente su atención en la actividad de estos reyes de armas, dejando incluso en segundo plano el asunto político en el que están interviniendo, mostrando, por tanto, más interés por el mensajero que por el mensaje. Este es el caso, por ejemplo, de la actuación que recoge de un rey de armas de Carlos V en embajada ante el rey de Francia en 1528, en donde el asunto central que se acaba tratando con relación a esta embajada acaba siendo el trato recibido por el rey de armas en la corte parisina y las dificultades que tuvo en el desempeño de su misión ${ }^{96}$, lo que también sería recogido por otros cronistas $^{97}$.Del mismo modo, se muestra igualmente muy atento a la embajada protagonizada aquel mismo año por un rey de armas de Inglaterra y otro de Francia recibidos por Carlos V, hallándose en Monzón ${ }^{98}$. Sabemos que la recepción de aquellos reyes de armas se produjo en la posada del duque de Calabria, don Fernando ${ }^{99}$, por lo que, dada su relación epistolar con Fernández de Oviedo, bien hubiera podido ser este la fuente de información. Igualmente se muestra atento a la presencia de los reyes de armas en el levantamiento de pendones por doña Juana, sabida la muerte de la reina Isabel ${ }^{100}$, o la presencia de reyes de armas en los anuncios de noticias relevantes para el reino en plaza pública ${ }^{101}$.

Elogio de Isabel. Sobre el conjunto de los monarcas de que trata el manuscrito, es sin duda la figura de Isabel la Católica la que concentra el mayor esfuerzo apologético por parte del autor, lo que le lleva a dar por título a un capítulo" 102 "Capítulo de las grandes exçelençias de la reyna doña Ysabel"103, si bien esta relación de alabanzas no queda limitada a dicho capítulo. En este sentido, este planteamiento apologético tiene un desarrollo textual muy paralelo al que nos ofrece Fernández de Oviedo en textos conocidos de su pluma ${ }^{104}$, siendo el punto de arranque la incomparabilidad de

${ }^{96}$ BL-MS, fol. 72rv.

${ }^{97}$ Mexía, Pero: Historia del emperador Carlos V, edic. de Juan de Mata Carriazo, Madrid, 1945, pp. 514-521.

${ }^{98}$ BL-MS, fol. 68.

${ }^{99}$ Mexía, fol. 68.

100 "Siendo huérfana España de su reyna y señora según que ya arriba aueis oydo, començaron a temerse las guerras y males antiguos que en el tiempo de su vida adormidos estauan, mas nuestro Señor Dios, auiendo misericordia de España, quiso voluer toda esta tristura en placer por que en este día que la reyna murió el Rey don Fernando con grandes lágrimas salió de su palaçio con muchidumbre de grandes destos reynos, y subiendo en un cadahalso, guardando las ceremonias y solenidades que en este tal caso se requería, hizo levantar pendones por la reyna doña Juana, su hija, que hera casada, como arriba deximos, con el príncipe don Felipe, con trompetas y reyes de armas, teniendo un pendón real el duque de Alua en sus manos, dixeron Castilla, Castilla, Castilla por la reyna doña Juana, nuestra señora” BL-MS, fol. 21r.

101 "El presidente arçobispo de Granada y el liçenciado Çapata y licenciado Múxica, doctor Carbajal, licenciado Santiago, Polanco, Aguirre y Coalla, con un rey de armas, mandaron pregonar e publicar paz e aliança perpetua entre sus altezas y el rey de Françia, como adelante está escripto por virtud destos poderes ya dichos". BL-MS, fol. 39v.

${ }^{102}$ BL-MS, fol. 19r.

${ }^{103}$ Es esta misma voluntad de describir las excelencias de la reina Isabel la que está presente en el elogio que le dedica en AVALLE-ARCE, II, p. 466: "Pero aunque no sea yo tan suficiente ni tal mi estilo para nauegar o discurrir por la muy alta e profunda mar de sus excelencias".

${ }^{104}$ Véase, por ejemplo, AvalLe-ARCE, II, pp. 466-467. 
los méritos de la reina castellana con respecto a cualquier otra reina coetánea o de otro tiempo ${ }^{105}$.

Genealogías y sucesión en la ocupación de cargos y dignidades. Para muchos personajes que aparecen citados, aprovecha su introducción en el relato para trazar los datos genealógicos, apuntando el nombre de padres o, a veces, incluso de abuelos, en especial, si éstos fueron personajes especialmente relevantes. También, en ocasiones, alude al origen de sus casas. Está igualmente muy atento a dar noticia de la muerte y sucesión de dignidades, sobre todo presta atención a la sucesión al frente de las distintas mitras episcopales y cargos relevantes con especial relieve en el gobierno y la milicia, tales como presidentes del Consejo Real, de la Audiencia Real o capitanes generales. Cuando se produce un nombramiento, si este es especialmente relevante, no es raro que trate de trazar la línea de procedencia familiar del que recibe el cargo $\mathrm{y}$, a veces, también del que lo deja. En fin, son todas ellas circunstancias que parecen ponernos sobre la pista de quien bien pudiera estar trazando ya el proyecto que acabará conduciendo a las Batallas y quinquagenas, donde estos asuntos se convierten en elemento vertebrador del conjunto del relato, de modo que dejar asentada su memoria se muestra con frecuencia como el objetivo último de tan extensa obra.

Madrid. Lugar de nacimiento de Gonzalo Fernández de Oviedo, extensamente aludido por diversos conceptos en su obra ${ }^{106}$, tiene una presencia muy destacada en el manuscrito londinense, produciéndose a veces una notable precisión en las ubicaciones dentro de esta ciudad, señalándose incluso la hora en la que en tal lugar de Madrid acaece el acontecimiento al que se refiere, lo que sólo parece comprensible para quien bien conoce su geografía urbana y posee fuentes muy directas de lo su-

105 "No pasemos so silençio tantas excelençias como esta reyna tubo, tratemos de algunas dellas pues que la natura no crió otra semejable que en sus reynos así gouernase que si la antigüedad alabó a Semíramis o a las amazonas o algunas otras hembras por fechos claros que hiziesen o por grandeza o fermosura que tobiesen todas estas si algunas graçias touieron con algunas mançellas las ensuçiaron, mas esta exçelentísima reyna doña Ysabel desde el día de su nasçimiento fasta el día de su muerte se halló siempre no menos fuerte que constante y magnánima auer sobrepujado a las que avemos arriba dicho. Viuió tan sobre vondad compuesta que nunca demasiada palabra alguno se halla auerle oydo que dixese. Fue castísima muger, llena de todo honestidad. Enemiçisima de palabras ni muestras desonestas. Nunca se vio en su persona cosa yncompuesta. Nunca se halló en su obras cosa mal hecha, ni en su palabras palabra mal dicha. Por çierto se deue creer que heran sus pensamientos muy santos y justos que aunque muger, y por eso de carne flaca, hera alumbrada de dones superuos y de gracia espiritual, fue fiel amiga subjeta. Cara y carísimo a su marido, fauoresçedora de las mugeres bien casadas y de lo contrario muy enemiga. Cathólica cristianísma, devota fidelísima, a Dios madre muy piadosa, a sus súbditos, reyna muy justa a sus vasallos, dada a contemplaçión y dedicada a Dios, ocupáuase en los offiçios diuinos muy continuamente, ni por eso dexava la gouernaçión humana. Hera religiosa y deuota a todas las religiones. Tenía gran caridad, suma prudençia, grandísimo ferbor de justiçia, mucha modestia con las cosas, gran honestad y estudio, de bida apostada, hera enxemplar de buenas y loables costumbres, hera manánima, liberalísima en merçedes e dones repartidos por todo el mundo a los embaxadores que venían de otros prínçipes, a sus servidores e criados muy grata, a todos los suplicantes y negoçiadores, de sus reynos muy apaçible, descargó en su vida y en días de salud y alegría grandes sumas y cuentos de dineros de su descargo, deudas y promesas y obligaçiones que dende su tierra hera obligada y también descargó las conçiençias de sus progenitores. Su mansedumbre fue admirable, su magestad mayor, jamás vista su miseridordia y piedad, todo el orbe la canta, mas así usaba de piadad que no olbidaba el coptuo (sic) dela justicia". BL-MS., fols. 18v-19r. Siguen las alabanzas a la reina en los folios siguientes, fols. 19r-20v.

${ }^{106}$ Perea Rodríguez, Oscar: "Madrid en la obra genealógica de Gonzalo Fernández de Oviedo", Madrid en el tránsito de la Edad Media a la Moderna, Madrid, 2008, pp. 301-329. 
cedido $^{107}$. Aprovecha alguna circunstancia para poner de relieve el protagonismo de algún personaje, destacando su origen madrileño. Aporta datos genealógicos extensos y personajes destacados de la familia de los Vargas ${ }^{108}$, a la vez que no faltan las referencias a miembros de otras familias madrileñas como la de los Zapata ${ }^{109} \mathrm{o}$ los Coalla ${ }^{110}$, presentes también en la obra de Fernández de Oviedo ${ }^{111}$.

América. Teniendo en cuenta la trayectoria vital de Fernández de Oviedo, algo que puede llamar la atención para una obra atribuible a este autor es la parca referencia que hace a todo lo relacionado con América. De entrada, hay que tener en cuenta, tal como señalaré luego, la perspectiva desde la que se aborda el conjunto del Catálogo Real en su planteamiento original, que no era otra que abordar los asuntos desde la perspectiva del protagonismo personal de los monarcas, de manera que casi podría afirmarse que el enfoque del autor es aún más personalista en torno a la figura regia que lo que sería propio de una crónica. Así se sitúa más en la línea de una galería de personajes en donde aquellos que motivan el relato son los propios reyes y sus particulares comportamientos, rasgos y acciones.

Con relación al primer viaje de Colón, reflejado en el texto como por quien parece nada saber de la realidad de Indias, habría que tener en cuenta que, a pesar de que la segunda parte del Catálogo Real se completaría después de 1532, me parece bastante probable que, tal como indicaba antes, todo lo que antecede a la llegada de Carlos $\mathrm{V}$ estuviera ya redactado en 1516 y que los acontecimientos referentes al reinado de Isabel I se hubieran redactado con bastante inmediatez a las Cortes de Toro de 1505. El primer viaje de Oviedo a América se produce en 1514, embarcándose el 11 de abril de este año ${ }^{112}$, por lo que cuando escribe sobre el viaje de Colón me parece muy probable que Oviedo careciera por completo de experiencia americana ni de especial interés e información sobre este tema, lo que justificaría la liviandad y evidente falta de noticias precisas con que aborda este asunto. Es, además, evidente, que los acontecimientos que desarrolla antes de 1516 no los retoca posteriormente, por lo que la imagen que él está dando del viaje de Colón es la propia de quien nada sabe de América y maneja, en consecuencia, imágenes tópicas bajo el concepto medieval de tierras extrañas de seres bestiales ${ }^{113}$.

107 "Y en Madrid, miércoles, a las quatro, después de medio día, diez del mes de septiembre de mill e quinientos e diez y seis años en las plaças de Sant Saluador y del arrabal, el presidente arçobispo de Granada y el liçenciado Çapata y licenciado Múxica, doctor Carbajal, licenciado Santiago, Polanco, Aguirre y Coalla, con un rey de armas, mandaron pregonar e publicar paz e aliança perpetua entre sus altezas y el rey de Françia". BL-MS., fol. 39v.

${ }^{108}$ BL-MS, fol. 74r. Sobre los Vargas, con referencias que recuerdan a las del manuscrito, AvalLEARCE, II, pp. 324-328.

${ }^{109}$ BL-MS, fols. 40r, 44v, 45v.

${ }^{110}$ BL-MS, fols, 40r, 45v.

${ }^{111}$ Avalle-Arce, I, p. 319, para los Zapata y pp. 333-337, para los Coalla.

112 Ballesteros, p. 91.

113 "Hera ganado ya como dicho es el Reyno de Granada y buelto a la observançia de la cristiana religión, y como dentro de los términos deste reyno no oviese provinçia ni mençión que de cristianos no fuese con el mismo herbor y deseo que estos reyes celadores de la fee tenían, mandaron hazer una flota grande, aumentándola y basteçiendola de todas las cosas que sobre la agua para ella necesarias fuesen, pusieron capitanes en las naos para que fuesen por la mar para que qualesquier ynsulas que hallasen que de cristianos no fuesen ocupadas las ganasen, y después a nuestra santísima fe catholica conuertiesen 
En cambio, ya en un momento más tardío, es llamativo que, aun siendo asunto bien ajeno a los objetivos propios del texto, el autor se detenga en dar noticia de la fundación del patriarcado de las Indias Occidentales, a lo que alude en la narración de los acontecimientos referidos al año $1522^{114}$, recayendo tal dignidad en la persona de Antonio de Rojas Manrique ${ }^{115}$ :

Al qual sucedió en el obispado de Palençia don Antonio de Rojas, obispo que hera de Mallorca y arçobispo de Granada y dende a poco con el episcopado de Burgos, alcançó ser patriarca de las Yndias, la qual dignidad de nueuo se ynstituyó por el papa allende otras patriarcales con la autoridad desta dignidad y porque también por su vez de ante quisiera quitarse de sí el cargo de la gouernaçión de la república que tenía como presidente del consejo real de término de apartarse de cuidados y cargos" $" 16$.

Ya en otro orden de cosas, por lo que se refiere a la perspectiva de conjunto desde la que se aborda la redacción del manuscrito, hay que tener en cuenta para valorar el sentido de la narración que, en coincidencia con lo que acaece en la primera parte del Catálogo Real, tal perspectiva no viene sujeta por lo que serían los rasgos característicos de una obra cronística, sino que responde más bien al modelo de galería de personajes, en este caso reyes, al estilo de Claros varones de Castilla de Pulgar y Generaciones y semblanzas de Pérez de Guzmán, obras que bien conocía y apreciaba, tal como manifiesta Oviedo en alguna ocasión ${ }^{117}$. Todo ello explicaría que el planteamiento de la obra tenga los siguientes ingredientes principales, en perfecta coherencia con el planteamiento que sigue en las Quinquagenas de la nobleza:

- Establecer un perfil humano de cada uno de los monarcas que trata.

- Dar especial relieve a acontecimientos en los que participó personalmente.

\footnotetext{
los moradores que en las tales ynsulas hallasen. Y así partieron navegando estos que en las naves yban contra la parte oriental y descubrieron unas grandes ynsulas muy fértiles y abundosas. Y esas ynsulas estavan llenas de gente vestial que ydolatrava, a los quales el santo evangelio no les avia sido predicado, y conquistándolos los que en las naves yvan, las ganaron y pusieron nombres propios en ellas y sometiendolos debaxo de la sujeçión y mandado de la corona real destos exçelentísimos príncipes y reyes. Los moradores que en estas ynsulas hallados fueron estauan desnudos y en modo de vestias fieras vibían y carnes humanas por su manjares comían y hazían otras novedades no oydas antes. Afirman muchas personas de autoridad que estas gentes así adoravan a los demonios que muchas vezes le hablaban y resçibían las respuestas de sus preguntas, y esto les veyan hazer muchos de los españoles que allá estavan en estas dichas ynsulas. Fueron hallados muchos mineros, así de oro como de plata, y de otros metales, de lo qual fue gran suma y cantidad de oro, ymbiando a sus altezas como lo que a Salamón de Tarso se lee aver ymbiado, construyeron y dotaron en estas yslas una yglesiaarchiepiscopal metropolitana y tres yglesias cathedrales con sus perlados, los quales convertiesen a nuestra cristiana fee aquellas barbáricas gentes, y asi fue con ayuda de nuestro señor dios fecho, que viben oy en conosçimiento y alabança de su verdadera fee, fue pues ayuntado nueva y incógnita tierra a nuestra España que se llama las Yndias, todo esto en la filiçidad próspera destos cathólicos prinçipes. BL-MS. fols. 12v-13r.

${ }^{114}$ Es también esta fecha la que se da para dicha fundación en Fernández Duro, Cesáreo: "Noticias acerca del origen y sucesión del patriarcado de las indias occidentales", Boletín de la Real Academia de la Historia, VII (1885), pp. 197-215.

${ }^{115}$ López Gómez, Ángela: "Los presidentes del Consejo de Castilla" en Revista Hidalguía no 210 , pp. 678-679 y Redondo Cantera, Ma José, "Diego Siloé, autor del sepulcro de Don Antonio de Rojas", Boletín del Seminario de Estudios de Arte y Arqueología: BSAA, 44 (1978), pp. 446-451.

${ }^{116}$ BL-MS, fol. 55rv.

${ }^{117}$ AvalLe-Arce, II, pp. 402.
} 
- Dedicar especial atención a los asuntos de la corte y a lo que era expresión de la "cortesía" propia del momento.

- Favorecer un criterio apologético y reivindicativo de la figura de cada monarca, lo que motivaría sus problemas para abordar la figura de Enrique IV hasta que consiguió disponer del texto de Enríquez del Castillo.

- Conceder una atención constante a lo que son datos relativos a la ocupación de cargos y dignidades y al establecimiento de genealogías de los grandes personajes de su tiempo, en coincidencia con la perspectiva propia de sus Batallas y quinquagenas.

\section{ALGUNOS APUNTES SOBRE EL ESTILO NARRATIVO}

Tras la publicación de su novela de caballerías Claribalte en 1519, Fernández de Oviedo declara su intención de sujetar en el futuro su obra a dos criterios, el estilo común y llano, carente de afectación, y el rechazo de lo novelesco para volcarse en dejar memoria de los hechos ciertos ${ }^{118}$. Probablemente sería difícil encontrar dos rasgos que mejor caracterizasen formalmente el tono con el que se aborda el texto considerado. Junto a ello, hay una voluntad muy evidente de ser preciso en los datos, lo que, a veces, supone una cierta acumulación de referencias en cuanto a señalar con la mayor exactitud posible lugares, momentos, participantes, procedencias... Todo ello parece revelar una marcada voluntad de convencer al lector de que lo que se narra sucedió exactamente así, sin margen de variación.

Dentro de esta voluntad de dar certeza y verosimilitud a lo narrado está el hecho de incluir con alguna frecuencia cartas in extenso o documentos que forman parte del propio asunto tratado, de manera que algunos hechos que se narran quedan circunscritos a lo que es la transcripción directa de una carta o de un documento oficial. Este uso de la carta nos pone sobre la pista de un autor que depende precisamente de la recepción de cartas para saber de algunos de los hechos que quiere narrar. Del mismo modo, es una preocupación común en la cita de personajes el que éstos queden perfectamente identificados para el lector, lo que a veces lleva al autor a relacionar referentes de parentesco que disipen cualquier duda con respecto a quien sea el personaje aludido.

Siendo las grandes ceremonias celebratorias, sobre todo en forma de desarrollo de grandes cortejos y entradas reales, uno de los temas recurrentes, la incorporación a lo narrado de la transcripción completa de carteles e inscripciones suele ser otro recurso común en la exposición de este tipo de acontecimientos, a la vez que se presta puntual atención a reflejar símbolos, gestos, vestuario y otros detalles que refuercen la autenticidad de lo descrito. Del mismo modo, ocupando los acontecimientos militares un lugar importante en la obra, la exaltación del sentimiento patriótico tiene una presen-

${ }^{118}$ FABREgAT, p. $66-67$. 
cia especialmente marcada, sobre todo para referirlo a destacados jefes militares ${ }^{119}$ como, en particular, al rey Fernando ${ }^{120}$.

Por otra parte, esta búsqueda de estilo llano y sin afectación se hace compatible con la introducción con no poca frecuencia de referencias a autoridades de muy diversa procedencia, en ocasiones de origen bíblico, otras se trata de autores clásicos grecolatinos o, finalmente, autores fundamentales del pensamiento teológico cristiano. Me limitaré a destacar una infrecuente presencia, en este caso perteneciente a la literatura latina, pero que, precisamente por su rareza e infrecuencia, el que se de en el manuscrito y también en la obra conocida de Fernández de Oviedo hace que tome valor significativo para la asociación de este manuscrito a dicho autor. Se trata de Julio Capitolino, uno de los autores que participa en la Historia Augusta ${ }^{121}$. El autor del manuscrito utilizará la semblanza realizada por este autor romano del emperador Antonino Pío para poner de relieve el carácter piadoso y caritativo de Enrique IV que, de acuerdo con la textualidad del relato, "tenía mucha compasión de los miserables" 122.

En el manuscrito, como en la primera parte del Catálogo Real, y de manera aún más resumida en el Epílogo, queda claro que la intención del autor no es el desarrollo pormenorizado de los hechos acaecidos en el devenir de cada reinado, al estilo de lo que sería la crónica tradicional. Por el contrario, de lo que se trata es de establecer

119 "Van por capitanes generales desta gente don Fadrique de Toledo, duque de Alua y el conde de Venabente, tomando esta empresa por seruicio de la reyna en tanta estima como caualleros de mucha fidelidad a su reyna y de mucho amor a su patria. El conde de Lemos, como sabidor fuese de la copia de gente que contra él venía, usando de mejor consejo, dio de su voluntad libre y desembargadamente la dicha villa y fortaleza de Ponferrada a la persona que para resçebirla los del consejo ymbiaron". BLMS, fol. $24 \mathrm{v}$.

120 "Y partiendo el rey don Fernando de su ciudad de Valençia, dende a poco tiempo por que el amor que a su patria tenía le hizo tan presto venir con tanta y tan entera voluntad como a este reyno tenía quando con la reyna doña Ysabelhera casado y por la naturaleza que en él tiene". BL-MS, fol. 25r.

${ }^{121}$ Julio Capitolino, historiador romano que vivió a caballo de los siglos III y IV d.C., fue uno de los autores de la Historia Augusta, en la que se reúnen treinta y cuatro biografías de emperadores romanos de los siglos II y III d. C. Entre las biografías que se le atribuuyen se cuentan las de Antonino Pío, Marco Aurelio, Lucio Vero, Pertinax, Clodio Albino, Opilio Macrino, los dos Maximinos, los tres Gordianos, y Máximo y Balbino. Avalle-Arce da referencias sobre la utilización de Julio Capitolino por Gonzalo Fernández de Oviedo. Avalle-Arce, Las memorias, I, pp. 119-120.

122 "Hera esta rey don Enrrique, allende otras virtudes muchas que tenía, era dado al exército delas armas, muy manso a sus súbditos, muy feroz contra sus enemigos, perdonaba ligeramente de sus yerros a los que reconosçiendo su culpa demandauan perdón, hera muy más humano y manso y humilde que la maldad del tiempo lo demanda, hera muy clemente, enemigo de toda crueldad, finalmente perdonaua los errores y junto a esto, con ser piadoso, tenía mucha compasión de los miserables, por que no menos que otro emperador Adriano, muchas vezes visitaua a sus seruidores aunque de muy vaxa manera y con manjares de su mesa mesma los administraua y probeya sus neçesidades, y olvidado de la alteza de su reyno, negoçiaba todo, officios de piadad que pertenesçían al prouecho de qualquiera hombre, aunque fuese persona privada. Y esto imitando al emperador Antonio Pío, del qual dize Julio Capitolino que como muchas vezes visitase a un caballero enfermo, que con él se avía criado y en su visitación se avaxase con él a obras viles, aunque piadosas y por tanto desagradase a muchos como si lo tal a Reyno conviniese, él riéndose dixo: ni la dignidad ni el imperio quitan la afición, ni con la alteza de la dignidad derogan las obras de piadad, ansí que allende de las obras pías, es de tanta mansedumbre y de tan agradable halago que no castiga así fáçilmente a los que contra sí y su magestad vea ser culpados y a los que contra él se levantauan con un divino ánimo los admitía a la mesma familiaridad en que antes los tenía”. BL-MS, 5rv. 
un perfil biográfico de cada monarca a partir de lo que fueron sus rasgos personales característicos y una selección de aquellos acontecimientos de su reinado que, bajo el criterio del autor, caracterizaban de una manera más significativa el desarrollo del mismo. En tal sentido, se percibe una unidad de criterio expositivo de estos textos.

Ya en otro orden de cosas, puede señalarse que las consideraciones de índole lingüísticos señaladas por Romano de Thuesen con relación a la primera parte del Catálogo Real son igualmente constatables. Así, se observa la presencia de los rasgos que dicha autora ponía de relieve en los siguientes términos ${ }^{123}$ :

La variable más notable en el texto es gráfica y atañe al uso de z, ç, s y ss, g, j y x. La c se presenta cedillada en casi un cien por ciento de los casos. Existen también vacilaciones entre b y v, y se mantiene la grafía de $\mathrm{u}$, con el doble valor de vocal y semivocal latina y v, en algunos casos empleada con valor vocálico de $u$. No existe en absoluto la alternancia de $\mathrm{d}$ y $\mathrm{t}$ finales, adoptándose la forma con $\mathrm{d}$ y se generaliza el uso de $\mathrm{h}$ inicial, si bien se observan unos pocos ejemplos de conservación de f (fecho, fijo, si bien éste último es ampliamente superado por el empleo de hijo). Aparecen algunas vacilaciones vocálicas en las sílabas no acentuadas (previlegio, siguir, vertuoso). De las formas verbales llaman la atención el futuro de verbos como tener, terná(tendrá), poner, porná (pondrá), venir, verná (vendrá) y la conservación de la forma arcaica del participio y gerundio de ser, sey doy seyendo respectivamente. En cuanto a los cultismos, se adopta en algunos casos la fonética vulgar para su escritura : seta, ynorançia, perfeçión; en otros se prefiere la forma latina: redemptor, tractado, escriptura, y en un tercer caso, conviven ambas opciones: sancto y santo, dubda y duda, sobjuzgar y sojuzgar".

\section{CONCLUSIONES PROVISIONALES}

Tras el desarrollo de la pesquisa que aquí se ha presentado y que no se agota en el análisis aquí trazado a la espera del desarrollo completo de la edición del manuscrito londinense, y aun aceptando que no cabe ofrecer pruebas definitivas sobre la autoría y plena identificación del manuscrito aquí considerado, resulta difícil sustraerse a la hipótesis que aquí propongo de que estemos en presencia de una cierta versión de la hasta ahora perdida segunda parte del Catálogo Real de Castilla, texto, el de esta segunda parte, varias veces aludido en su obra por su propio autor, Gonzalo Fernández de Oviedo.

De acuerdo, por tanto, con esta hipótesis que ahora someto a la crítica, este manuscrito vendría a constituir ese texto, acaso no en su versión definitiva, que, tal como había asegurado repetidamente Gonzalo Fernández de Oviedo, arrancaría desde la muerte de Juan II de Castilla hasta llegar a la actualidad. Una actualidad que, en unas ocasiones, había situado en la conquista de La Goleta en 1535 y en otras ocasiones había situado en las cortes de Monzón de 1542, siendo los tres hitos señalados, el de comienzo, y los dos de final, compatibles con lo que en el manuscrito se encuentra; pues si por un lado, el último hecho relevante que se ofrece es el de la toma de La Goleta y las consiguientes celebraciones, las cortes de Monzón de 1542 están presentes también, no bajo narración de acontecimientos, sino mediante plasmación

${ }^{123}$ Romano de Thuesen, p. 28. 
de documento testimonial, mostrando la intención de incorporar tal hecho al cuerpo narrativo.

Acabada la redacción del Catálogo Real en 1532 con la muerte de Juan II de Castilla, dio comienzo inmediatamente a su continuación, para la cual ya probablemente tenía escrita una parte, la que iba hasta 1516, puesto que, tal como se expresa en el BL-MS, para ese año, el autor cuando se refiere al príncipe Carlos está hablando en términos de esperanza futura de su venida. Esto haría pensar en que alcanzada esa fecha se produciría transitoriamente el abandono de su redacción. Esta circunstancia, el que ya se tuviera redactado previamente hasta 1516, contribuiría a explicar que circulase alguna versión de lo que había escrito hasta ese momento y que podría dar lugar a alguna copia tardía independiente de esa parte, como la que se conoce como la Continuación de la crónica de Pulgar por un anónimo, ampliamente coincidente en su textualidad, aunque no en su totalidad, con el BL-MS para el periodo 1474-1516. Bien cabe pensar que lo correspondiente a ese periodo podría haber sido redactado, como ya señalé antes, entre algún momento bastante próximo en su principio a 1505 y a 1516, para su final, notándose un importante bache narrativo para el periodo1513 y 1516, en coincidencia precisamente con el tiempo en que Fernández de Oviedo se ausentó de España con motivo de su primer viaje a América.

Del mismo modo, tengo la impresión de que el manuscrito londinense no representa la versión definitiva de esta obra, tal como lo demuestran algunos espacios en blanco y la presencia de documentos posteriores a la fecha final de redacción que harían pensar que su final se querría llevar más allá. El desarrollo narrativo se interrumpió en 1536, probablemente en coincidencia con la propia crisis vital que, a no dudar, debió de experimentar el autor habida cuenta de las circunstancias personales ya referidas. Esto no impidió que se mantuviera viva la voluntad de completar el proyecto, lo que justificaría la recopilación de algunos documentos con los que probablemente se pretendía ampliar los contenidos de capítulos ya redactados, así como llevar el relato hasta 1542, momento en el que, probablemente, comenzó a dejarse de lado el proyecto ante la fuerza que iban tomando otras iniciativas historiográficas. En este sentido, el manuscrito londinense interpretado bajo esta óptica me inclina a pensar que no se puede asegurar que se acabase tal proyecto, siendo en mi opinion el BL-MS la versión más extensa que, por ahora, conoceríamos de esa segunda parte del Catálogo Real que, hasta el momento, se tenía por perdida o por inexistente.

A la vista de estas consideraciones, me parece que resulta muy oportuno traer aquí cierta reflexión de José Amador de los Ríos con relación a la obra en conjunto de Fernández de Oviedo y, muy en especial, con relación al Catálogo Real: "lo que de todo se deduce es que de las obras de Oviedo se hubieron de sacar, á trozos, diferentes traslados, poniendo cada copista al que extractaba el título que mejor hubo de parecerle" 124 .

Según esta interpretación, que me parece acertada, la conocida hasta ahora como Continuación de la crónica de Pulgar por un anónimo, fue uno de esos trozos en el que básicamente se incluía el reinado de los Reyes Católicos, según el Catálogo Real, con ausencia de alguno de sus capítulos, como, por ejemplo, el referido al comienzo del reinado y con mayor desarrollo de otros contenidos, principalmente referidos a

${ }^{124}$ Amador de los Ríos, p. XCI. 
la guerra de Granada, lo que hace prensar en la existencia de varias versiones, mientras que el resto de lo que va hasta 1516, casi todo, era sustancialmente lo mismo, con ocasionales y muy aisladas modificaciones de redacción. Así, el reinado de los Reyes Católicos concebido por Fernández de Oviedo, de acuerdo con esta hipótesis, sería el resultado de "pegar" esos dos trozos, siguiendo la terminología de Amador de los Ríos, en su parte no coincidente. Del mismo modo, teniendo en cuenta que la Continuación viene de una copia de 1607, claramente posterior al texto aquí tratado, estaríamos ante la evidencia de que alguna circulación, aunque bajo forma "troceada", habría tenido el texto del autor madrileño.

Más allá de estas consideraciones de índole textual, el manuscrito analizado también ofrece algunas reflexiones en cuanto a lo que sería el uso de la historia en el contexto del momento de su redacción. En mi opinión, el gran motivo de fondo que subyace en el proyecto historiográfico del autor es que, a partir de que la historia hispánica ha entroncado con la historia imperial, es necesario disipar cualquier sombra sobre la dignidad de la memoria trastámara como prestigioso precedente de un emperador Carlos elevado al más alto rango del modelo heroico renacentista. En cierta medida, se trataba de demostrar que el liderazgo político del emperador Carlos se había alcanzado sobre la base de una herencia dinástica, la recibida por el emperador, a la que se unía la expresión de una abnegación heroica y de un sentimiento patriótico específicamente hispánicos presentes en muchos ejemplos individuales y en no pocas acciones colectivas y anónimas que, tal como se afirma, no conviene dejar en el olvido, de los que, en consecuencia, se trata de dar cumplido testimonio en la obra. Todo ello resultaba muy coherente con ese rasgo atribuido a la obra de Fernández de Oviedo como creadora y legitimadora de sentimientos ${ }^{125}$. Tal perspectiva se aborda desde la visión propia de una biografía de transición entre medioevo y renacimiento, como la de un autor, como el aquí considerado, en donde intereses y perspectivas en muchos aspectos todavía tardomedievales se ponen bajo una escenografía y se cubren con unos oropeles propios de la primera modernidad.

${ }^{125}$ García Hernán, Enrique: "La España de los cronistas reales en los siglos XVI y XVII", Norba. Revista de Historia, 19 (2006), pp. 125-150. 